\title{
CAPABILITIES AND UTILITIES*
}

Carmen Herrero**

WP-AD 95-06

* This paper was written while I was visiting the University of California, Davis, and the Institute for Advanced Studies, Vienna, in 1994. I am most grateful to John Roemer for his help and suggestions. Thanks are due to Subir Chattopadhay, Iñigo Iturbe-Ormaetxe and Antonio Villar for useful comments. Financial support from the DGICYT under project PB 92-0342 is also acknowledged. The usual caveat applies.

** Instituto Valenciano de Investigaciones Económicas and University of Alicante. 
Editor: Instituto Valenciano de Investigaciones Económicas, S.A. Primera Edición Marzo 1995.

ISBN: 84-482-0901-X

Depósito Legal: V-1205-1995

Impreso por Copisteria Sanchis, S.L., Quart, 121-bajo, 46008-Valencia.

Printed in Spain. 


\section{CAPABILITIES AND UTILITIES}

\section{Carmen Herrero}

\section{A B S T R A C T}

In this paper we address the problem of looking for resource allocation mechanisms which would be accepted as equitable from Sen's point of view, in a framework of economic environments. We simplify the idea of equalizing capabilities by means of the equalization of a capability index. Then, we analyze the relationship between capability and utility, and provide characterization results on mechanisms giving us allocations which are capability lexmin suprema.

KEYWORDS: Capabilities; Functionings; Equitable Allocations. 


\section{INTRODUCTION}

Rawls (1971, 1982) and Sen $(1980,1985,1992,1993)$ have each put forth theories in which a natural criterion for distributive justice relies on guaranteeing everybody equality of opportunity. The main underlying idea is that as long as there is equality of access to education, positions, jobs, and that all hiring is meritocratic, then the resulting distribution of income is looked at as just. The crucial point is, then, to make clear the meaning of the term equality of opportunity. For Rawls, equality of opportunity means equality of some specific primary goods which are necessary for a person, independently of her conception of welfare or utility. For Sen, goods or commodities are not important by themselves; what is important is what goods can do for people. Some goods enable people to function in various ways: to move, to be healthy, to develop some personal characteristics, to be happy, etc.. In this spirit, Sen calls the set of functionings available to a person, her capability. Capability is thus a set of vectors of functionings, reflecting the person's freedom to lead one type of life or another. Sen's proposal of justice is, therefore, to equalize capabilities across agents, so that a distribution of goods is just, if it maximizes the set of functionings of that person whose set is the smallest one, or, in other words, to maximize the capability of the person having the smallest capability.

It seems clear that the well-being of a person depends upon the functionings achieved. Whether a person is well-nourished, in good health, etc., must be intrinsically important for the wellness of that person's 
being. Additionally, the capability of a person can be understood as the "set of opportunities to have well-being", and so it is also related with the well-being index the person achieves ${ }^{(1)}$.

Summarizing, there are two different concepts we can associate to every individual, namely, his capability set and his utility, related between them, and both depending upon the commodities the individual consumes (and probably also depending upon some other variables).

In this paper, we address the problem of looking for resource allocation mechanisms which would be accepted as just from Sen's point of view. In so doing, we start by suggesting a way of simplifying Sen's idea of capability by using a capaleility index which measures the ability of a

1 A point to be noticed is that, since the functionings of different people are different, the equalization of capabilities is quite a strong requirement. It is not enough to equalize access to education, jobs, etc, but it is also necessary to compensate people for those differences they are not responsible for, as is the case with natural talent, abilities, handicaps, or even the environment in which they are born.

Equalizing capabilities across agents, nevertheless, does not mean that we are equalizing the vector of functionings selected by those agents, since the selection involves a particular decision of every agent. Even if all the agents have the same capability set, their achieved functionings can (and in general would) be different. Therefore, an interesting point involves the relationship between the capability of a person and her well-being (or utility). Sen mentions several interpretations of well-being or utility indexes as wealth, happiness, standard of living or agency achievement. Among those indices, the so called "agency achievement" has also been used by Rawls under the name of degree of life-plan fulfillment, the idea being that happiness or personal well-being has to do with the extent to which a person is able to fulfill her life-plan. Life-plans vary from person to person, but this degree of fulfillment seems to be a sensible way of measuring utility. Actually, under conditions of risk neutrality, and Von Neumann-Morgenstern preferences, they can be identified [see Roemer (1994a)]. It is also interesting to notice that these degrees of life-plan fulfillment turn out to be interpersonally comparable. 
person to function. This simplification relies on Sen's suggestion of providing an "elementary evaluation" of the capability sets [see Sen (1992, pp. 50-51).

Then, we look for mechanisms providing allocations which could be deemed as just, in pure distribution problems. Following Sen's idea, an allocation is just whenever its corresponding capabilities are lexmin suprema. We provide a characterization result of this mechanism in a framework which mimics Roemer's (1988) bargaining in economic environments. In general, the allocations providing capability indexes leximin suprema are not Pareto Optimal in utility terms, since there is no general relationship between capability index and utility. Nonetheless, under some specific circumstances, we may find Pareto Optimal allocations in utility terms within the set of allocations that are capability lexmin suprema. Finally, we suggest a way of obtaining Pareto Optimal allocations respectful with a fair distribution of capabilities.

Section 2 analyzes the relationship among resources, functionings and capabilities. Section 3 contains a formalization of Sen's functioning approach. Section 4 is devoted to the characterization of the capabilities leximin suprema mechanism. Section 5 discusses conditions under which these allocations are Pareto Optimal in utilities. Finally, some additional remarks, suggestions and open questions are gathered in Section 6. 


\section{RESOURCES, FUNCTIONINGS AND CAPABILITY}

Consider the case of a single agent, and a set of relevant functionings for this agent: life-expectancy, level of nourishment, level of education, mobility, etc. Let us assume that we can measure the achievements of these functionings by means of adequate indices. Vectors of functionings belong to some space, which, for the sake of simplicity, is assumed to be $\mathbb{R}^{\mathrm{m}}$. Let $\mathbb{R}_{+}^{l}$ denote the commodity space, that is, a point $\mathrm{x} \in \mathbb{R}_{+}^{\ell}$ stands for a bundle of goods this agent may consume.

Commodity bundles influence the vectors of functionings the agent can achieve. There will also be other variables reflecting the achievable vectors of functionings, most significantly those related to personal will. For the sake of simplicity, let us consider only one of these variables, and call it effort; moreover, assume that effort takes values in some interval $E \subset \mathbb{R}_{+}$. Thus, the vectors of functionings available to the agent depend upon the resources he/she enjoys, and the amount of effort he/she decides to apply. In consequence, we may think of this relation as a correspondence $\mathrm{C}: \mathbb{R}_{+}^{\ell} \times E \rightarrow \mathbb{R}^{m}$, where $\mathrm{C}(\mathrm{x}, \mathrm{e}) \subset \mathbb{R}^{\mathrm{m}}$, and $\mathrm{C}(\mathrm{x}, \mathrm{e})$ describes the vectors of functionings available to the agent, under resources $\mathrm{x}$ and effort e. In Sen's terminology, $\mathrm{C}(\mathrm{x}, \mathrm{e})$ denotes the capability set of the agent under resources $\mathrm{x}$ and effort e. In order to make the construction minimally operational, we consider the following assumptions:

(1) Status-quo: $C(O, e)$ is a singleton, $C(0, e) \in \mathbb{R}^{m}$. 
(2) Resources monotonicity ${ }^{(2)}$ : If $\mathrm{x}>\mathrm{x}^{\prime}$, then $\mathrm{C}(\mathrm{x}, \mathrm{e}) \geq \mathrm{C}\left(\mathrm{x}^{\prime} \mathrm{e}\right)$ for all $e \in E$.

(3) Comprehensiveness: $\quad \forall \quad(x, e), \quad C(x, e)$ is comprehensive, i.e., if $f \in C(x, e)$, and $C(0, e) \leq f^{\prime} \leq f$, then $f^{\prime} \in C(x, e)$

(4) Closedness: $\forall(x, e), C(x, e)$ is closed in $\mathbb{R}^{m}$.

(5) Upper Hemi Continuity: $\forall(x, e),\left\{x_{p}\right\} \rightarrow x,\left\{e_{p}\right\} \rightarrow e, f_{p} \in C\left(x_{p}, e_{p}\right)$, if $\left\{f_{p}\right\} \rightarrow f$, then $f \in C(x, e)$.

(6) Full dimension: $\exists(x, e) \in \mathbb{R}_{+}^{n} \times E, f \in C(x, e), f>C(0,0)$.

(7) Decreasing marginal capabilities: $\forall(x, e), \quad \forall 0<\lambda<1, \lambda C(x, e) c$ $C(\lambda x, e)$

These assumptions deal with the way the capability set changes with resources and effort. We assume (1) that under no resources a unique vector of functionings is achievable for each level of effort. $\mathrm{C}(0,0)$ can be looked at as the "natural capability of the agent". (2), If the resources increase, then the capability set does not shrink; (3) any vector with less level of functionings is also achievable (we may associate this property with functionings free disposal); (4) any limit point of achievable 
functionings is also achievable, (5) small changes in the resources and/or in effort give raise to small changes in the capability set, (6), by some specific amount of effort and some commodities, the agent can strongly dominate the natural vector of functionings, and (7), the transformation of commodities in capabilities presents "decreasing returns to scale".

It may be noticed that most likely some of the functionings will be positively related, so, in looking for some minimal regularity, convexity of the capability sets has to be avoided. Comprehensiveness seems to be a more palatable assumption.

Notice that we do not assume effort monotonicity. In principle, effort is costly in utility terms. Additionally, among the relevant functionings we may include some positively related with the utility of the agent. Thus, whereas bigger effort in principle may enlarge the level of achievement for same functionings, it possibly will decrease the level of achievement of some others.

Thus, under our assumptions, the set $\mathrm{C}(\mathrm{x}, \mathrm{e})$ looks like a non convex but comprehensive bargaining set. This set increases with the resources and possibly "balances" with the effort [see Figure 1]. 


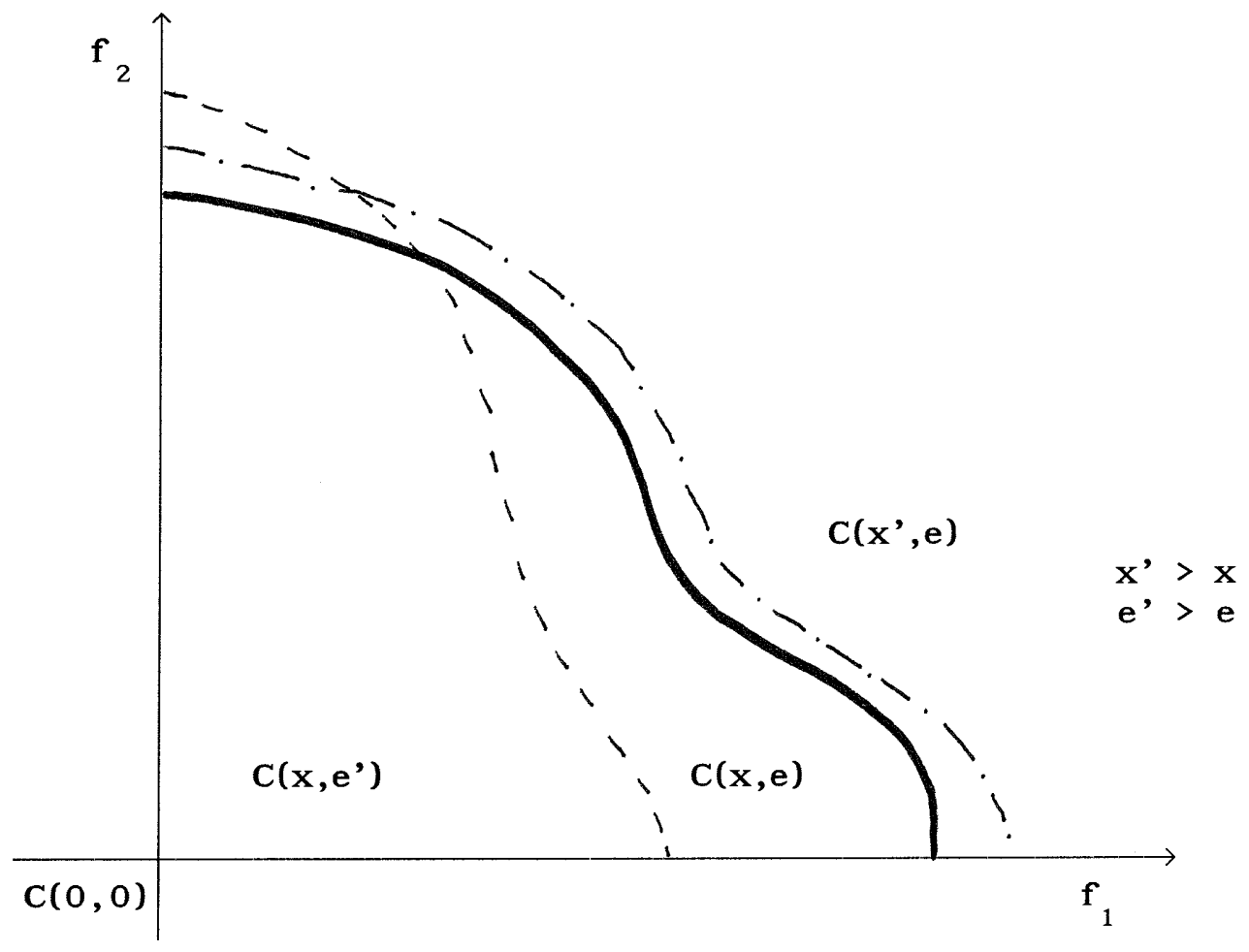

FIGURE 1

Let us now analyze the decision problem of the agent when he receives the bundle of goods $\mathrm{x}$. We may think that the utility of the agent depends upon the resources he consumes, the functionings achieved, and the level of effort, and for simplicity we may assume it is representable by means of a function $v: \mathbb{R}^{l} \times \mathbb{R}^{m} \times E \longrightarrow \mathbb{R}$. Thus, given bundle $x$, he chooses a level of effort, $e^{*}$, and a vector of functionings $f^{*} \in C\left(x, e^{*}\right)$, such that he maximizes $v(x, f, e)$ within his accesible functionings and effort levels $\left[v\left(x, f^{*}, e^{*}\right) \geq v(x, f, e)\right.$, for all $e, f$, such that $\left.f \in C(x, e)\right]$.

Suppose now that we consider two different bundles of resources $\mathrm{x}, \mathrm{x}^{\prime}$, and the associated capability sets $C(x, e), C\left(x^{\prime}, e\right)$. If $C(x, e)<C\left(x^{\prime}, e\right)$ for all $\mathrm{e} \in \mathrm{E}$, one can safely claim that the agent has higer capability under $x$ 
than under $x$ '. Nevertheless, this relationship does mean neither that the achieved functionings under $x^{\prime}$ are better than the achieved functionings under $\mathrm{x}$, nor that the achieved utility under $\mathrm{x}^{\prime}$ is bigger than the achieved utility under $\mathrm{x}$ :

Example: Consider two goods, two functionings and an individual such that $C(x, e)=C^{(3)}\left\{\left[\frac{x_{1}+x_{2}}{2},\left(x_{1}+x_{2}+e\right)\right],\left[\left(x_{1}+x_{2}-e\right),\left(x_{1}+x_{2}\right)\right]\right\}$.

Suppose $E=[0,1], x=(1,0), y=(0, .8)$. Then, $C(x, e) \supset C(y, e)$ for all $e$ [see figure 2]. Let the preference relation of the agent be representable by function $v[x, f, e]=\left(f_{1}+x_{1}\right)\left(f_{2}+10 x_{2}\right)$. For bundle $x=(1,0), e^{*}=1$, $\mathrm{f}^{*}=(1 / 2,2)$, and $\mathrm{v}\left(\mathrm{x}, \mathrm{f}^{*}, \mathrm{e}^{*}\right)=3$, for bundle $\mathrm{y}=(0, .8), \mathrm{e}^{*}=0, \mathrm{f}^{*}=$ $(.8, .8)$, and $v\left(y, f^{*}, e^{*}\right)=7.04$ [see figure 3].

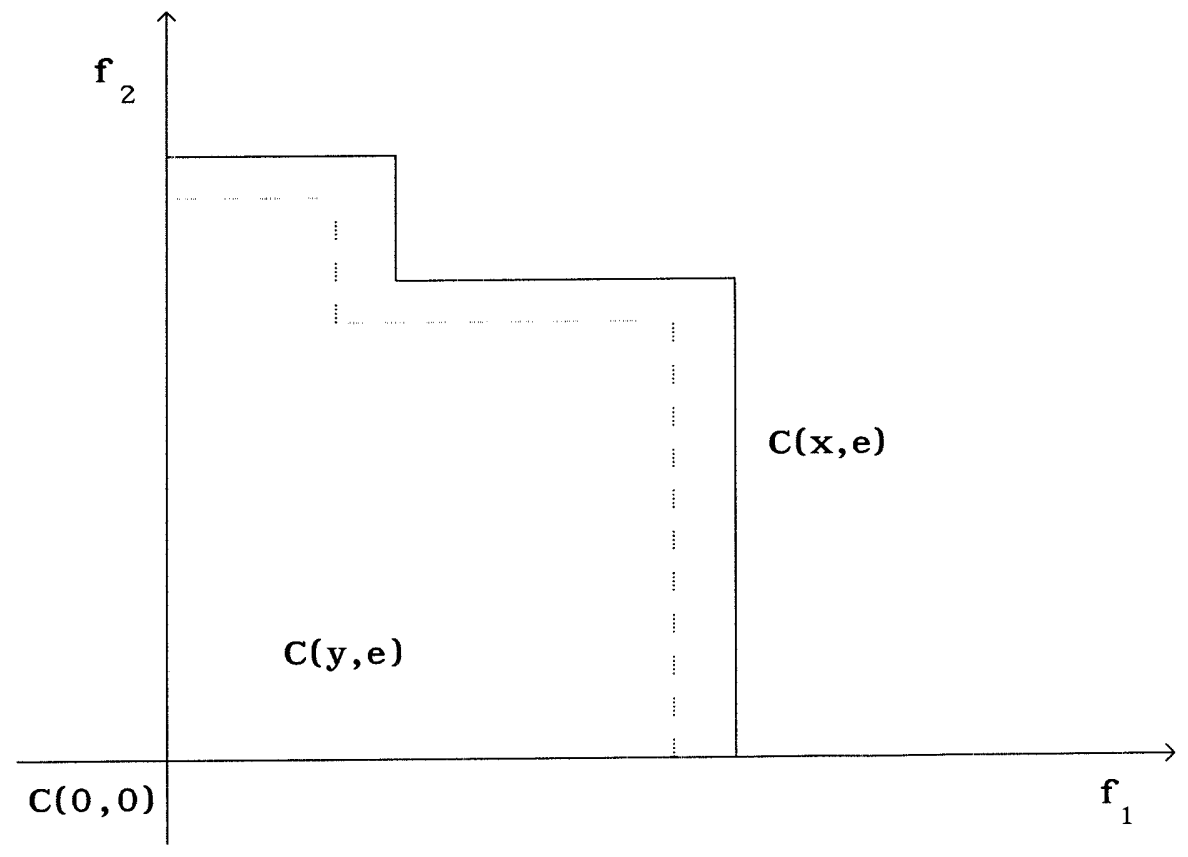

FIGURE 2 


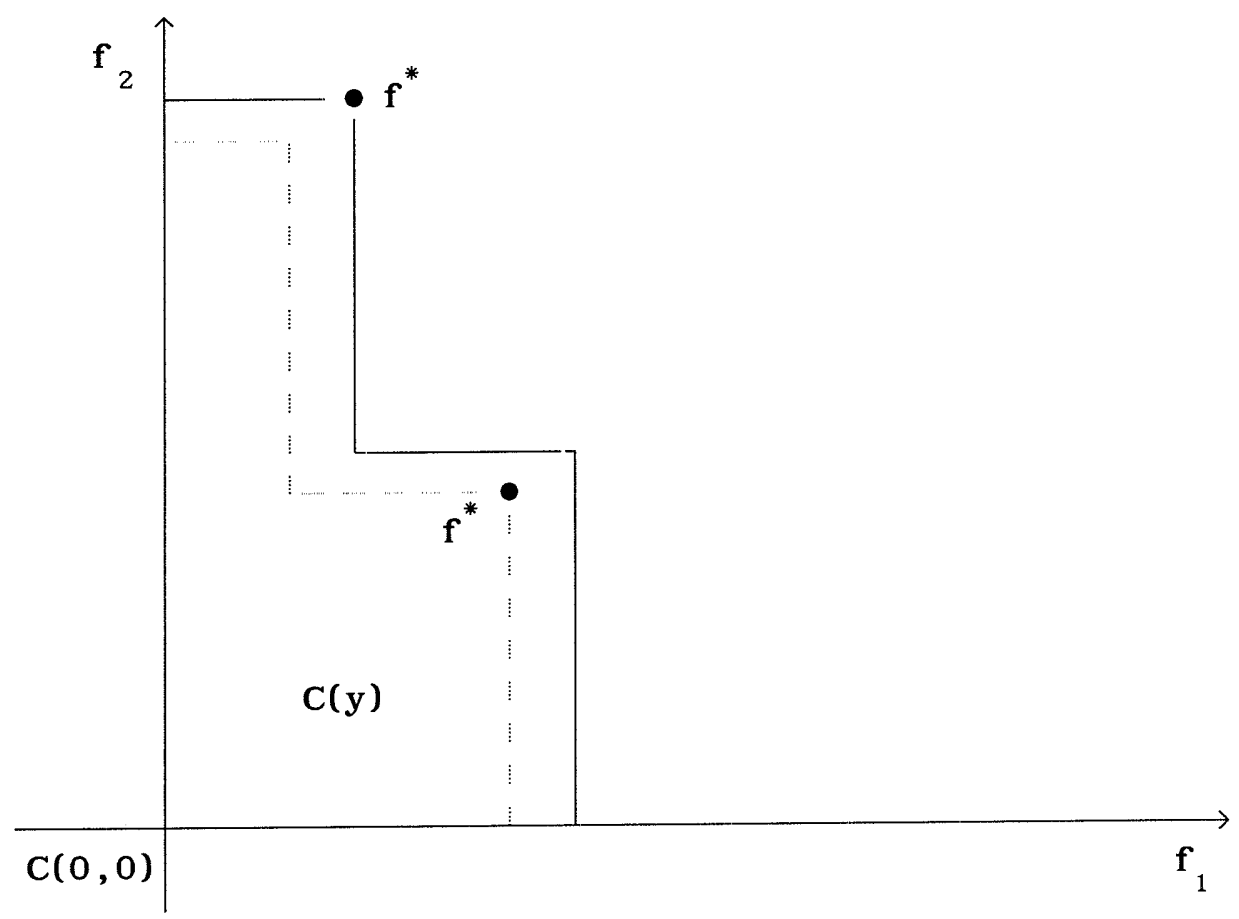

FIGURE 3

Previous example is anything but pathological: we may think of functioning 1 as increasing with effort, and functioning 2 as decreasing with effort. Moreover, the agent cares not only about the level of functionings achieved, but also about which particular commodities they come from. This example also ilustrates the type of difficulties we are going to face in this approach: (1) If we are concerned about apportunities, in terms of achievable functionings, in general we cannot compare opportunities for different bundles of goods, even for a single agent; (2) even in the case in which it is clear that some bundle of goods provides the agent with a wider opportunity set (in terms of functionings) than other bundle, it does not mean that the agent will end up in the first case with a better vector of functionings; (3) The relationship between opportunities and achieved utility is by no means straightforward. 
Problems (2) and (3) above have to do with the idea of responsibility. Whenever the agent has at her disposal a set of vectors of functionings, it is up ta her which particular vector to choose (and also, it is her responsibility the chosen level of effort).

Thus, a natural way of measuring the opportunities of the agent coming from a particular bundle of goods $x$, is by considering $C(x)=\underset{e \in E}{U} C(x, e)$ as the capability set of the agent under bundle of gaads $x$.

If effort is not observable, the maximizing procedure of the agent gives raise to some $\mathrm{f}^{*} \in \mathrm{C}(\mathrm{x})$, and we may think of $\mathrm{f}^{*}$ as the preferred element in the capability set $C(x)$, [see figure 4]. In this case, we may define $u(x)=v\left(x, f^{*}, e^{*}\right)$, as a way of measuring the satisfaction of the agent in terms of the goods he consumes.

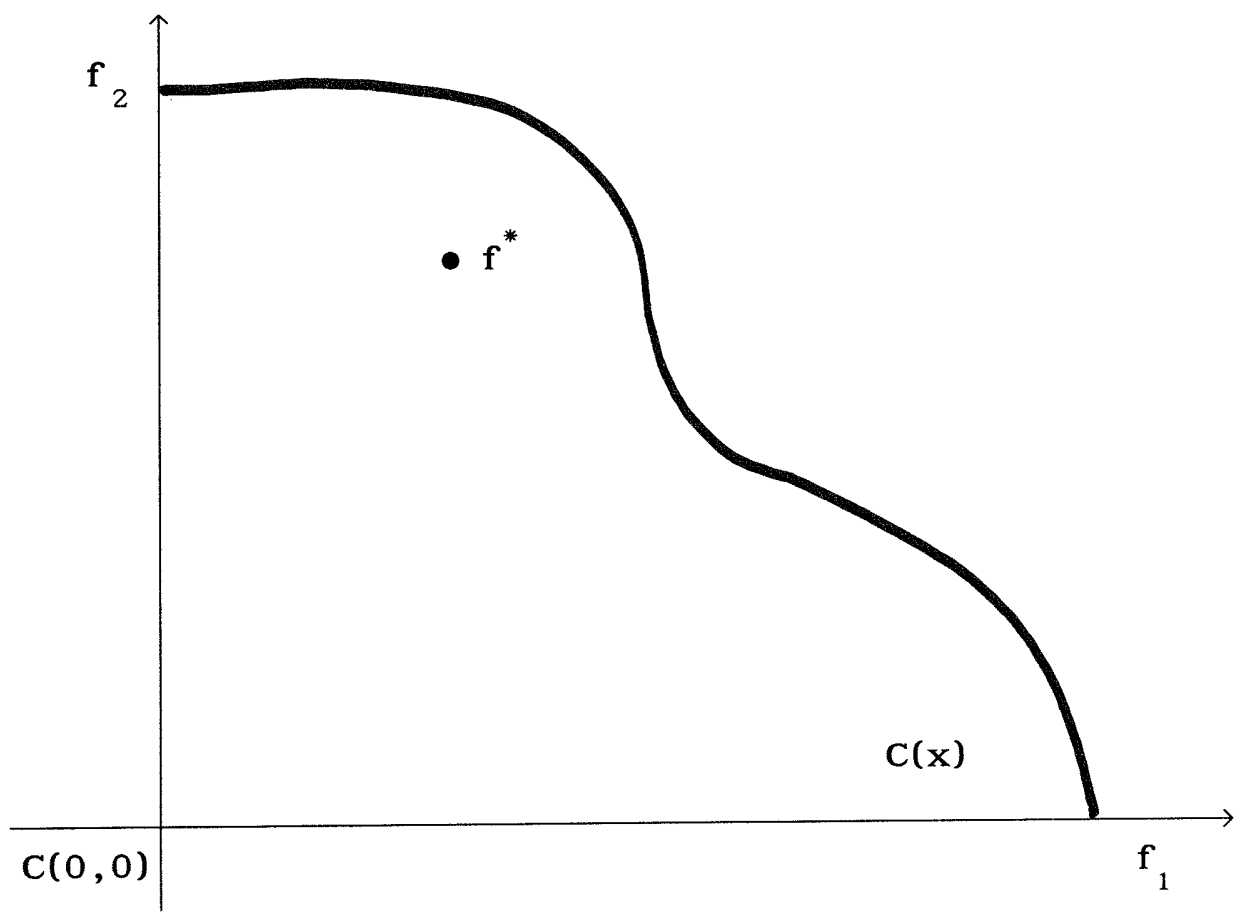

FIGURE 4 
Remark: if $\mathrm{v}[\mathrm{x}, \mathrm{f}, \mathrm{e}]=\mathrm{w}(\mathrm{f})^{(4)}$, or $\mathrm{v}(\mathrm{x}, \mathrm{f}, \mathrm{e})=\tau(f, e)$, and $\mathrm{C}(\mathrm{x}, \mathrm{e})>\mathrm{C}(\mathrm{y}, \mathrm{e})$ for all e, then $C(x) \supset C(y)$ implies $u(x) \geq u(y)$.

\section{CAPABILITY INDEX AND FAIR ALLOCATIONS}

So far, for a given bundle of resources, we attached to the individual his capability set $\mathrm{C}(\mathrm{x})$, and suggested a way of obtaining his utility function. By means of the utility function we can always compare the level of well-being of the individual under two different bundles of commodities, but this is not the case with the capability sets. In general, neither $C(x) \supset C(y)$, nor $C(y) \supset C(x)$. Therefore, in capability terms, $x$ and $y$ are in general non comparable.

Now suppose a planner has to allocate a bundle of $\ell$ goods among a group of $\mathrm{n}$ agents. The planner's target consists of equalizing the capabilities of the different individuals, as a way of equalizing the access to well-being. We may assume that the planner has complete information about the capability correspondences of the agents, that is, he

4 The idea of the utility function being dependent on the functionings and not on the commodities goes back to Lancaster's idea on the demand for characteristics [see Lancaster (1966)]. We may think of the functionings as characteristics of the commodities dealing with the way a person functions in some particular respects. On a similar interpretation in the context of health, see Pereira (1993). 
knows the correspondences $\mathrm{C}_{i}: \mathbb{R}_{+}^{\ell} \times \mathrm{E}_{\mathrm{i}} \rightarrow \mathbb{R}^{\mathrm{m}}, \mathrm{i}=1, \ldots, \mathrm{n}$. Even in this case, equalization of capability sets may be impossible, since we cannot in general compare $C_{i}(x)$ and $C_{j}(y)$ [actually even $C_{i}(x)$ and $C_{i}(y)$ cannot be compared].

A way of avoiding this problem is by attaching some capability index to the capability sets $\mathrm{C}_{\mathrm{i}}(\mathrm{x})$. Assume that the planner considers some specific combination of functionings as the ideal functioning vector ${ }^{(5)}$, f*. Then, a way of calibrating the capability sets consists of looking at those achievable vectors with identical proportion of functionings as that of the ideal functioning vector ${ }^{(6)}$. If the largest $\lambda$ such that $\lambda f^{*} \in C_{i}(x)$ is larger than the largest $\lambda$ with $\lambda \mathrm{f}^{*} \in \mathrm{C}_{i}(\mathrm{y})$, we may say that agent $i$ has a higher capability index under $\mathrm{x}$ than under $\mathrm{y}$. Similarly, we may compare capabilities across agents, by means of comparing the achievable vectors of a fixed functionings proportion.

Thus, we may define $c_{i}(x)=\max \lambda \mid \lambda f^{*} \in C_{i}(x)$. Notice that the chosen vector of functionings is weakly optimal in $C_{i}(x)$.

5 Depending upon the specific problem faced by the planner, it may be not so difficult to construct the ideal functioning vector. For instance, if we deal with problems of access to health care in different countries, the relevant functionings may be associated with the way some services are covered (hospitals or doctors per capita), or some demographic data (infant rate of survival, life-expectancy), etc. Then, the ideal functioning vector may correspond to the achievements in more developed countries. In relation to these functionings, see Sen (1992).

6 The idea of choosing the direction of the ideal functionings vector as a way of associating a number to any capability set is related to some rules to choose a particular point in a bargaining set, and in particular, goes back to the proportional solution proposed by Chun \& Thomson (1992) in bargaining problems with claims. 
Some immediate properties of $c_{i}$ are the following ${ }^{(7)}$ :

(1) $c_{i}: \mathbb{R}_{+}^{\ell} \rightarrow \mathbb{R}_{+}$is well defined, increasing and continuous for all $\mathrm{i}=$ $1, \ldots, \mathrm{n}$.

(2) $c_{i}$ is concave.

Whenever the capability sets are defined, for any feasible allocation, $\mathrm{x}_{1}, \ldots, \mathrm{x}_{\mathrm{n}}$, the capability indexes $\mathrm{c}_{\mathrm{i}}\left(\mathrm{x}_{\mathrm{i}}\right)$ are well defined. The problem the planner faces is to look for a feasible allocation such that $c_{1}\left(x_{1}\right)=\ldots=$ $c_{n}\left(x_{n}\right)$ lor to distribute the resources in such a way that the capability indexes of the agents are equal]. It may be that there is no allocation solving the problem, and in such a case, we may look for an allocation equalizing capabilities as far as possible, namely, attaching the highest capability to that agent with the smallest capability index. Under our assumptions, for any bundle of resources, the solution of that problem is non empty ${ }^{(8)}$.

7 Alternative proposals for attaching capability indexes with similar properties can be obtained by considering some particular distances from the ideal vector to the different capability sets, or by means of using specific measures on the sets $\mathrm{C}(\mathrm{x})$ or by suitably adapting rules for comparing sets. Ideas on preferences for flexilility [Kreps (1979)], or of extending orderings from a set to the power set [Puppe (1994)], may be helpful.

8 In order to have the solution well defined, it is not necessary that capability sets fulfill property (7). This property guarantees concavity of the capability indexes, but it is not required for the existence of the fair solution. 
It may be noticed that the planner concentrates all the relevant information about the capability set in the capability index. Thus, we may think of the planner's ordering over vectors of functionings as a leximin ordering on the components scaled by the ideal vector. On the other hand, the planner is only concerned about the accessibility of the agents to this particular vector of functionings. It may be, nonetheless, that actual choices of the agents deviate from the proposed target, due to agents' freedom of choice between several ways of transforming commodities into functionings. Since the planner's concern is related to the accessibility and not with the final realization of his proposed target, this way of equalizing is respectful with the responsibility of the agents in their choices. Even if the agents have identical sets of functionings, it could be that their final utility levels are different, and it does not go against our concept of equity ${ }^{(9)}$.

\section{AXIOMATIC CHARACTERIZATION OF SEN'S FAIR ALLOCATIONS}

Let us consider the problem of distributing a bundle of goods among a group of agents in an "equitable way". We shall follow an axiomatic approach, namely, to adopt some general principles the planner finds

9 The most prominent idea in contemporary theories of distributive justice is that personal responsibility justifiably restricts the degree of outcome equality [see Arneson (1989), Bossert (1993), Cohen (1989), Dworkin (1981), Roemer (1994b)]. 
reasonable and require that the resource allocation mechanism considered satisfies them. Moreover, these principles have to apply to any passible problem of a certain type the planner could face. So, let us start by considering the class of problems we are going to deal with. A particular problem is identified by means of the relevant information available to the planner. This information, in our case, is summarized by the following list:

$\mathrm{n}$ : number of agents

$\ell$ : number of commodities

$\mathrm{w}$ : available amount of the different commodities $\left(\mathrm{w} \in \mathbb{R}_{+}^{\ell}\right)$.

$c_{i}, i=1, \ldots, n\left(c_{i}: \mathbb{R}_{+}^{\ell} \rightarrow \mathbb{R}\right)$

$c_{i}, \quad i=1, \ldots, n$, constitute the relevant characteristics of the agents. $c_{i}$ represents an index of capability agent $i$ achieves whenever a certain bundle of goods is attached to him. We assume that the planner has complete information on the relevant data for any problem he faces. Thus, a problem is completely specified whenever the planner knows the following list: $\langle\mathrm{n}, \ell, \mathrm{w}, \mathrm{c}\rangle, \quad \mathrm{c}=\left(\mathrm{c}_{1}, \ldots \mathrm{c}_{\mathrm{n}}\right)$. Let us now assume that the capability functions present some regularities, namely, they are drawn from a particular family of mappings ${ }^{(10)}$ :

For $\ell \in \mathbb{N}$, consider $\mathscr{G}^{\ell}=\left\{\mathrm{f}: \mathbb{R}_{+}^{\ell}->\mathbb{R} \mid \mathrm{f}\right.$ are monotone, continuous and concave\}.

10 Notice that by means of the construction suggested in Section 3 , the capability indexes belong to $\mathscr{C}^{\ell}$. 
Consider now the class $\sum$ of problems $\phi=\langle\mathrm{n}, \ell, \mathrm{w}, \mathrm{c}\rangle$ where $\mathrm{w} \in \mathbb{R}_{+}^{\ell}$, $c=\left(c_{1}, \ldots, c_{n}\right), c_{i} \in \mathscr{C}^{\ell}$ for all $i$.

Let us interpret $\phi$ in the following way: We consider a group of $n$ agents and a bundle of $\ell$ goods. Take the units of the goods such that prices are equal to 1 . The agents are characterized by functions $c_{i}$, the capability index of agent $i$, which provides us with a measure of the capability set of agent $i$, in terms of the bundle of commodities he consumes. This capability has a certain 'initial value' $\left[c_{i}(0)\right]$ which can be associated with the natural capability of agent $i$, and measures the capability achievable by the agent under no goods. $c_{i}$ weakly increases with $\mathrm{x}$, that is, if we provide some goods to the agent, she increases her capability (probably up to a point).

From now on, let us denote for an allocation $\mathrm{x}=\left(\mathrm{x}_{1}, \ldots, \mathrm{x}_{\mathrm{n}}\right), \mathrm{x}_{\mathrm{i}} \in \mathbb{R}_{+}^{\ell}$, $c(x)=\left[c_{1}\left(x_{1}\right), \ldots, c_{n}\left(x_{n}\right)\right]$

For a given $\phi=\langle\mathrm{n}, \ell, \mathrm{w}, \mathrm{c}\rangle \in \sum$,

$$
\mathrm{Z}(\phi)=\left\{\mathrm{x}=\left(\mathrm{x}_{1}, \ldots, \mathrm{x}_{\mathrm{n}}\right), \mathrm{x}_{\mathrm{i}} \in \mathbb{R}_{+}^{\ell}: \sum_{i=1}^{\mathrm{n}} \mathrm{x}_{\mathrm{i}} \leq \mathrm{w}\right\}
$$

is the set of feasible allocations of $\mathrm{w}$ among the $\mathrm{n}$ agents.

$$
\mathscr{C}(\phi)=\left\{\left(\bar{c}_{1}, \ldots, \bar{c}_{n}\right) \in \mathbb{R}^{n}: \exists x \in Z(\phi), c(x)=\left(\bar{c}_{1}, \ldots, \bar{c}_{n}\right)\right\} \text { is the }
$$
capability passibilities set for problem $\phi . \mathscr{C}(\phi)$ is closed and convex.

$$
\mathrm{P}_{\mathrm{c}}(\phi)=\left\{\mathrm{x} \in \mathrm{Z}(\phi) \text { i if } \mathrm{y} \in \mathbb{R}_{+}^{\ell \mathrm{n}} \text {, and } \mathrm{c}(\mathrm{y})>\mathrm{c}(\mathrm{x}) \text {, then } \mathrm{y} \notin \mathrm{Z}(\phi)\right\}
$$

$\mathrm{P}_{c}(\phi)$ is the set of c-Pareta aptimal paints in $\mathrm{Z}(\phi) . \mathrm{P}_{c}(\phi)$ is a nonempty closed set, for all $\phi \in \sum$ (because of continuity of $\mathrm{c}$ ). 
Definition 1: An allacation mechanism $F$ is a correspondence which associates to each problem $e \in \sum$ a set of feasible allocations $F(\phi) c$ $\mathrm{Z}(\phi)$.

The following are properties a mechanism can fulfill:

Fullness: Let $\phi=\langle\mathrm{n}, \ell, \mathrm{w}, \mathrm{c}\rangle \in \sum$, and $\mathrm{x} \in \mathrm{F}(\phi)$. If for some $\mathrm{y} \in \mathrm{Z}(\phi), \mathrm{c}(\mathrm{x})=$ $c(y)$, then $y \in F(\phi)$.

Fullness asks for the mechanism to choose all the allocations associated with given points in capability space. The underlying idea is that if we face two allocations which are indifferent in capabilities terms, they are indistinguishable.

Capabilities Pareto Optimality (CPO): $\forall \phi \in \sum, \mathrm{F}(\phi) \subset \mathrm{P}_{c}(\phi)$.

Anonymity (AN): Let $\phi=\langle\mathrm{n}, \ell, \mathrm{w}, \mathrm{c}\rangle \in \sum$, and let $\pi: \mathrm{N} \rightarrow \mathrm{N}$ be any permutation. Consider now $\phi^{\prime}=\langle\mathrm{n}, \ell, \mathrm{w}, \pi \mathrm{c}\rangle$. Then, if $\mathrm{x} \in \mathrm{F}(\phi), \pi \mathrm{x} \in$ $F\left(\phi^{\prime}\right)$.

Ordinal Level Comparability for Capabilities (OLCC): Let $\phi=\langle n, \ell, w, c\rangle$, $\phi^{\prime}=\left\langle\mathrm{n}, \ell, \mathrm{w}, \mathrm{c}^{\prime}\right\rangle \in \sum$, where $c_{i}^{\prime}=g\left[c_{i}\right]$ for all $\mathrm{i}=1, \ldots, \mathrm{n}, \mathrm{g}: \mathbb{R} \longrightarrow \mathbb{R}$, increasing. Then, $F(\phi)=F\left(\phi^{\prime}\right)$.

For a problem $\phi=\langle\mathrm{n}, \ell, \mathrm{w}, \mathrm{c}\rangle$, we say that a good $(k)$ is a personal good for agent $i$, if $i$ is the only agent obtaining greater opportunities from being allocated good $k$. That is, if for all $j \neq i$, and for all $x_{j}, x_{j}$ 
such that $x_{j s}=x_{j s}^{\prime} s \neq k, c_{j}\left(x_{j}\right)=c_{j}\left(x_{j}^{\prime}\right)$, then $k$ is a personal good for agent i.

Consistency (CON): Let $\phi=\left\langle n, \ell+\ell^{\prime}, \quad\left(w, w^{\prime}\right), c\right\rangle$ be a problem such that $\left(x^{*}, y^{*}\right) \in F(\phi)$, where any of the $y$-goods are personalized goods for at most one agent each. Let $\mathrm{d}_{i}\left(\mathrm{x}_{\mathrm{i}}\right)=\mathrm{c}_{\mathrm{i}}\left(\mathrm{x}_{\mathrm{i}}, \mathrm{y}_{\mathrm{i}}^{*}\right)$, and consider the problem $\phi^{\prime}=\langle\mathrm{n}, \ell, \mathrm{w}, \mathrm{d}\rangle$. If $\phi^{\prime} \in \sum$, then $\mathrm{x}^{*} \in \mathrm{F}\left(\phi^{\prime}\right)$.

CON asks for two problems related in a very particular way. If there are some personal goods, and we allocate them under the prescription given by $F$, when we move into another problem of the class, then the way the mechanism recommend the distribution of goods $\mathrm{x}$, remains still valid.

Individual Resource Monotonicity (I.R.MON): Let $\phi=\langle\mathrm{n}, \ell, \mathrm{w}, \mathrm{c}\rangle, \phi^{\prime}=$ $\left\langle\mathrm{n}, \ell, \mathrm{w}^{\prime}, \mathrm{c}\right\rangle \in \sum$, with $\mathrm{w}_{\mathrm{k}}=\mathrm{w}_{\mathrm{k}}^{\prime}$ for all goods $\mathrm{k} \neq \mathrm{i}, \mathrm{w}_{\mathrm{i}}<\mathrm{w}_{\mathrm{i}}^{\prime}$ where $\mathrm{i}$ is a personal good for agent $j$. If $x \in F(\phi)$, then $\forall y \in F\left(\phi^{\prime}\right), c_{j}\left(x_{j}\right) \leq$ $c_{j}\left(y_{j}\right)$

Consider now the problem $\phi=\langle\mathrm{n}, \ell, \mathrm{w}, \mathrm{c}\rangle$ in $\sum$, and let $\mathrm{y} \in F(\phi)$. Now, assume that a part of the population leaves with the resources assigned to it by $\mathrm{y}$. Consider now the remaining agents, $\mathrm{M} \subset \mathrm{N}$, and the problem faced when the remaining resources have to be divided. Let us call this problem $\phi_{\mathrm{F}, \mathrm{M}, \mathrm{y}}$

Population Stability (PSTAB): Let M,N such that $\mathrm{M} \subset \mathrm{N}$, and $\phi=\langle\mathrm{n}, \ell, \mathrm{w}, \mathrm{c}\rangle$ $\in \sum, \mathrm{y} \in \mathrm{F}(\phi)$. Consider now $\phi^{\prime}=\phi_{\mathrm{M}, \mathrm{F}, \mathrm{y}}$. Then, $\mathrm{y}_{\mathrm{M}} \in \mathrm{F}\left(\phi^{\prime}\right)$. 
A mechanism $F$ satisfies PSTAB if, when a group of agents leave with the resources assigned to them, the way the mechanism distributed the resources among the remaining agents is still valid.

Previous properties have differing appeal: Efficiency is related toCPO; $\mathrm{AN}$ and I.R.MON are fairness principles: the planner has to treat identically those agents about whom he has identical information. On the other hand, there is no reason for an agent to be punished if an additional amount of a personal good for him becomes available; finally, CON and PSTAB are consistency principles.

These properties were introduced in the context of axiomatic bargaining in economic environments by Roemer (1988) as a way of reinterpreting the usual assumptions in classical axiomatic bargaining.

Now consider the lexicographic ordering $>^{\mathrm{L}}$ in $\mathbb{R}^{\mathrm{n}}: \mathrm{x}>^{\mathrm{L}}$ y $\left(\mathrm{x}, \mathrm{y} \in \mathbb{R}^{\mathrm{n}}\right)$ if there is an $i \in N$ with $x_{i}>y_{i}$ and $x_{j}=y_{j}$ for all $j<i$. Let $\alpha: \mathbb{R}^{n}-\rightarrow \mathbb{R}^{n}$ be such that for each $\mathrm{x} \in \mathbb{R}^{\mathrm{n}}$ there is a permutation $\pi$ of $\mathrm{N}$ with $\alpha(\mathrm{x})=\pi \mathrm{x}$ and $\alpha_{1}(\mathrm{x}) \leq \alpha_{2}(\mathrm{x}) \leq \ldots \leq \alpha_{\mathrm{n}}(\mathrm{x})$. The lexicographic maximin ordering $>^{\mathrm{Lm}}$ on $\mathbb{R}^{\mathrm{n}}$ is defined by $\mathrm{x}>^{\mathrm{Lm}} \mathrm{y}\left(\mathrm{x}, \mathrm{y} \in \mathbb{R}^{\mathrm{n}}\right)$ if $\alpha(\mathrm{x})>^{\mathrm{L}} \alpha(\mathrm{y})$.

Consider now the following subset of $\mathrm{P}_{c}(e)$ :

Definition 2: $L_{c}(\phi)$ is the set of those allocations such that their associated capability indexes are leximin suprema.

$$
\mathrm{L}_{c}(\phi)=\left\{z \in \mathrm{P}_{\mathrm{c}}(\phi) \mid \text { if } \mathrm{c}(\mathrm{y})>^{\mathrm{Lm}} \mathrm{c}(\mathrm{z}) \text {, then } \mathrm{y} \notin \mathrm{Z}(\phi)\right\} \text {. }
$$


If we take Sen's point of view, those allocations in $L_{c}(\phi)$ are fair for problem $\phi$, since they provide equal capability indices up to the point at which it does not come into conflict with optimality (in capability terms).

Some properties of $\mathrm{L}_{c}(\phi)$ are worth noticing: (1) $\mathrm{L}_{c}(\phi) \neq \varnothing$ and closed; (2) If $\mathrm{z}, \mathrm{t} \in \mathrm{L}_{\mathrm{c}}(\phi)$, then $\alpha[\mathrm{c}(\mathrm{z})]=\alpha[\mathrm{c}(\mathrm{t})]$. Actually, $\mathrm{L}_{\mathrm{c}}$ satisfies $\mathrm{a}$ stronger property:

Proposition 1.- For all $\phi \in \Sigma^{\mathrm{n}}$, for all $z \in \mathrm{L}_{\mathrm{c}}(\phi), \mathrm{c}(\mathrm{z})$ is unique in $\mathscr{C}(\phi)$.

PROOF: Let $z, t \in L_{c}(\phi)$, and assume that $c(z) \neq c(t)$. Since $\alpha[c(z)]=$ $\alpha[c(t)]$, the only possibility is that the permutations $\pi, \sigma: N-\rightarrow N$ such that $\pi \circ c(z)=\alpha[c(z)], \quad \sigma \circ c(t)=\alpha[c(t)]$, are different $(\pi \neq \sigma)$. Consider then $\mathrm{d}(\lambda)=\lambda \mathrm{c}(\mathrm{z})+(1-\lambda) \mathrm{c}(\mathrm{t}) \cdot \mathrm{d}(\lambda) \in \mathscr{C}(\phi)$, for $0 \leq \lambda \leq 1$, since $\mathscr{C}(\phi)$ is convex. So, we can find elements $x(\lambda) \in Z(\phi)$, with $c[x(\lambda)]=d(\lambda)$. Now, notice that $\mathrm{d}(\lambda)=\mathrm{c}[\mathrm{x}(\lambda)]>^{\mathrm{Lm}} \mathrm{c}(\mathrm{z})$, for $0<\lambda<1$, against the definition of $\mathrm{L}_{c}(\phi)$

Proposition 1 says that we do not face problems in which there are elements in $\mathrm{L}_{c}(\phi)$ such that the individuals getting the minimal capability level are different. As an immediate corollary, $L_{c}(\phi)$ turns out to be convex: If $z, t \in L_{c}(\phi), c(z)=c(t)$. Now consider $x(\lambda)=\lambda z+(1-\lambda) t$. Since all the $c_{i}^{\prime}$ 's are concave, $c[x(\lambda)] \geq \lambda c(z)+(1-\lambda) c(t)=c(z)=c(t)$. But then, $c[x(\lambda)]=c(z)$, as otherwise $z \notin \mathrm{P}_{c}(\phi)$.

Now, the following result is obtained (see Appendix): 
Theorem 1.- If a mechanism $F$ in $\sum$ satisfies fullness, OLCC, CON, CPO, AN, P.STAB. and I.R.MON, then $F=L_{c}$.

\section{5. $L_{c}$ AND THE DISTRIBUTION OF UTILITIES}

As we previously mentioned, in the general case no relationship can be derived between the orderings $c_{i}$ and $u_{i}$, and it is possible that within $\mathrm{L}_{c}(\phi)$ we cannot find any (weakly) utility Pareto optimal allocation.

Example: Consider two goods, two individuals, and two relevant functionings, such that:

$$
\begin{aligned}
& C_{1}(x, e)=\operatorname{Com}\left\{\left[\frac{x_{1}+x_{2}}{2},\left(x_{1}+x_{2}+e\right)\right],\left[\left(x_{1}+x_{2}-e\right),\left(x_{1}+x_{2}\right)\right]\right\} \\
& C_{2}(x, e)= \\
& \operatorname{Com}\left\{\left[\frac{0.64 x_{1}+x_{2}}{1.6}, \frac{0.64 x_{1}+x_{2}}{0.8}+e\right],\left[\frac{0.64 x_{1}+x_{2}}{0.8}-e, \frac{0.64 x_{1}+x_{2}}{0.8}\right]\right\}
\end{aligned}
$$

Suppose $E_{1}=E_{2}=[0,1], \omega=(1,0.8)$, and $z=(1,0), y=(0,0.8)$. Then, $C_{1}(z, e)>C_{1}(y, e)$ for all $e$, and $C_{2}(y, e) \supset C_{2}(z, e)$ for all e. Moreover, $C_{1}(z)=C_{2}(y)$. Therefore, the allocation $(z, y) \in L_{c}$, and it is the unique allocation in $\mathrm{L}_{\mathrm{c}}$, independently of the ideal vector of functionings we choose in order to define the capability index. 
Let $v_{1}[x, f, e]=\left(f_{1}+x_{1}\right)\left(f_{2}+10 x_{2}\right), v_{2}[x, f, e]=\left(f_{1}+10 x_{1}\right)\left(f_{2}+x_{2}\right)$. In this case, $u_{1}(z)<u_{1}(y)$, and $u_{2}(y)<u_{2}(x)$, and therefore the allocation $(z, y)$ is not Pareto optimal in utility terms.

It would be interesting to ask under what circumstances can we guarantee a pasitive relationship between $c$ and $u$, for some individual, namely, if it is possible that $c(x)>c(y)$ implies $u(x)>u(y)$. It may be so if, for instance, function $\mathrm{v}$ depends on the commodities and effort only through the vectors of functionings, or, alternatively, if the ordering induced by $\mathrm{v}$ is lexicographic on the functionings ${ }^{(11)}$.

Consider now the class $\mathbb{V}$ of problems $\phi=\langle\mathrm{n}, \ell, \mathrm{w}, \mathrm{c}, \mathrm{u}\rangle$, where $\langle\mathrm{n}, \ell, \mathrm{w}, \mathrm{c}\rangle$ $\in \sum$, and $\mathrm{u}=\left(\mathrm{u}_{1}, \ldots, \mathrm{u}_{\mathrm{n}}\right), \mathrm{u}_{\mathrm{i}}: \mathbb{R}_{+}^{\mathrm{n}} \rightarrow \mathbb{R}$ for all $\mathrm{i}=1, \ldots, \mathrm{n}$, and $\mathrm{c}_{\mathrm{i}}(\mathrm{x})>$ $c_{i}(y)$ implies $u_{i}(x)>u_{i}(y)^{(12)}$. Then we obtain the following result:

Proposition 2: For all $\phi \in \mathbb{V}, \mathrm{L}_{\mathrm{c}}(\phi) \cap \mathrm{P}_{\mathrm{u}}(\phi) \neq \varnothing$.

11 An alternative would be to divide the commodities into two groups for every individual: primary and secondary. A commodity is a primary good if it increases the capabilities, and it is secondary if it only influences the utility of the individual, but does not affect the functionings (in the case in which the utility is not a relevant functioning). Then, a lexicographic ordering on primary and secondary goods would also provide the required relationship. On this, see Roemer (1994a).

12

Notice that the evaluation by means of function $v$ allows for a wide range of possibilities. If "utility" is one of the relevant functionings, then $\mathrm{v}(\mathrm{x}, \mathrm{f}, \mathrm{e})=\mathrm{f}_{\mathrm{k}}$, for some particular $\mathrm{k}$, and the agent will choose that level of effort $e^{*}$ wich maximizes that perticular component on $C(x)$. Even more, if utility is the only relevant functioning, then we are back in the traditional analysis. If it is not so, then we assume that utility is something different of one precise functioning, and depends upon several of them. The positive responsiveness property relies then on the idea that functionings are important in the evaluation of utility, and actually, they are the only important parameters. 
PROOF: Suppose not. Then, there exists some $\phi \in \mathbb{V}$ such that for all $z \in$ $\mathrm{L}_{c}(\phi)$, there exists $\mathrm{y} \in \mathbf{Z}(\phi)$, such that $u(y)>u(z)$, i.e., $u_{i}(y)>u_{i}(z)$ for some $i, u_{j}(y) \geq u_{j}(z)$, for $j \neq i$. Then, $c_{i}(y) \geq c_{i}(z)$. Moreover, for $j$ $\neq i$, it cannot be $c_{j}(y)<c_{j}(z)$, for in that case, $u_{j}(y)<u_{j}(z)$. Thus, there are only two possibilities: either $c(y)=c(z)$, and then $z \in L_{c}(\phi)$, or $c(y)>c(z)$, which is impossible, since $z \in P_{c}(\phi)$.

That is, whenever a positive relationship exists between the capability indices and the utility functions for all indireiduals, some allocations in $L_{c}(\phi)$ are Pareto optimal in utility terms.

Consider now the following assumption:

(A) For some $i=1, \ldots, n$, and for all $x_{i}$, all $\varepsilon>0, \exists y_{i} \in N_{\varepsilon}\left(x_{i}\right)$, such that $c_{i}\left(x_{i}\right)<c_{i}\left(y_{i}\right)$

Assumption A asks for an agent whose capability index positively responds to some increment of commodities. Let us call $\mathbb{V}^{*}$ the set of problems in $\mathbb{V}$ for which (A) holds. Then, we obtain strong implications:

Proposition 3.- If $\phi \in \mathbb{V} *$, then $\mathrm{P}_{\mathrm{c}}(\phi) \subset \mathrm{P}_{\mathrm{u}}(\phi)$

PROOF: Let $z \in \mathrm{P}_{\mathrm{c}}(\phi)$ and assume that $\exists \mathrm{x} \in \mathrm{Z}(\phi)$ such that $\mathrm{u}_{\mathrm{k}}\left(\mathrm{x}_{\mathrm{k}}\right) \geq \mathrm{u}_{\mathrm{k}}\left(\mathrm{z}_{\mathrm{k}}\right)$ for all $k$, and $u_{j}\left(x_{j}\right)>u_{j}\left(z_{j}\right)$ for some $j$. Thus, $c_{k}\left(x_{k}\right) \geq c_{k}\left(z_{k}\right)$ for all $k$. If for some $i, c_{i}\left(x_{i}\right)>c_{i}\left(z_{i}\right)$, then we reach a contradiction, for then $c(x)$ would dominate $c(z)$, against the hypothesis of $z \in P_{c}(e)$. Thus, the only possibility is $c(x)=c(z)$. Choose $\varepsilon>0$ small enough as to $u_{j}\left(y_{j}\right)>$ 
$u_{j}\left(z_{j}\right)$ for $y_{j} \in N_{\varepsilon}\left(x_{j}\right)$. Now, by (A), we find $y_{i} \in N_{\varepsilon}\left(x_{i}\right)$, with $c_{i}\left(y_{i}\right)>$ $c_{i}\left(x_{i}\right)$. Let us call $y$ the allocation such that $y_{j}=x_{j}+x_{i}-y_{i}, y_{k}=x_{k}$ for $k \neq i, j$. Thus, $c(y)$ dominates $c(z)$, and we reach a contradiction since $z \in P_{c}(\phi)$

Corollary: In $\mathbb{V} *, \mathrm{~L}_{\mathrm{c}}=\mathrm{L}_{\mathrm{c}} \cap \mathrm{P}_{\mathrm{u}}$.

In $\mathbb{V}^{*}$, we may provide a characterization of $\mathrm{L}_{\mathrm{c}}$ by using a requirement weaker than fullness:

Weak Fullness: Let $\phi=\langle\mathrm{n}, \ell, \mathrm{w}, \mathrm{c}, \mathrm{u}\rangle \in \mathbb{V}^{*}$, and $\mathrm{x} \in \mathrm{F}(\phi)$. If for some $\mathrm{y} \in$ $Z(\phi), c(x)=c(y), u(x)=u(y)$, then $y \in F(\phi)$.

Theorem 2.- If a mechanism $F$ in $\mathbb{V} *$ satisfies weak fullness, CON, CPO,

OLCC, AN, P.STAB. and I.R.MON, then F $=L_{c}$.

PROOF. In Theorem 1, steps 1 to 5 , fullness is not used. Thus, we know that $F \subset L_{c}$. Suppose now there exists $z \in L_{c}(\phi)$, such that $z \notin F(\phi)$. Then, for any $t \in F(\phi), z$ and $t$ are $u$-Pareto non comparable, i.e., $\exists i, j \in N$, such that $u_{i}\left(z_{i}\right)>u_{i}\left(t_{i}\right)$, and $u_{j}\left(z_{j}\right)<u_{j}\left(t_{j}\right)$. But on the other hand, $c_{i}\left(z_{i}\right)=$ $c_{i}\left(t_{i}\right), c_{j}\left(z_{j}\right)=c_{j}\left(t_{j}\right)$.

Choose $\varepsilon>0$ small enough as to guarantee both $u_{i}\left(x_{i}\right)>u_{i}\left(t_{i}\right)$, and $u_{j}\left(v_{j}\right)$ $>u_{j}\left(z_{j}\right)$, for $x_{i} \in N_{\varepsilon}\left(z_{i}\right)$, and $v_{j} \in N_{\varepsilon}\left(t_{j}\right)$. Simultaneously, $c_{i}\left(x_{i}\right) \geq$ $c_{i}\left(t_{i}\right)$, and $c_{j}\left(v_{j}\right) \geq c_{j}\left(t_{j}\right)$. Let us consider the agent $k$ for which (A) holds. Since $i \neq j, \quad k$ has to be different either from $i, j$ or both. Suppose $\mathrm{k} \neq \mathrm{i}$, and choose $\mathrm{x}_{\mathrm{k}} \in \mathrm{N}_{\varepsilon}\left(\mathrm{x}_{\mathrm{k}}\right)$ such that $\mathrm{c}\left(\mathrm{x}_{\mathrm{k}}\right)>\mathrm{c}\left(\mathrm{z}_{\mathrm{k}}\right)$. Now, take $\mathrm{x}_{\mathrm{i}}$ $=z_{i}+z_{k}-x_{k}, x_{s}=z_{s}$, for $s \neq i, k$. Then, $c(x)>c(t)$. Contradiction, since $t \in P_{c}(\phi)$. Therefore, $L_{c}=F$. 
In $\mathbb{V}$ we are unable to make any distinction among those elements which are Pareto Optimal in utility terms. An alternative way of focusing the problem of allocating resources in $\mathbb{V}$ consists on looking for the "cheapest" way of guaranteeing the capabilities in $\mathrm{L}_{c}(\phi)$, then choose one of these allocations and distribute the remaining commodities in a way which could be considered acceptable. Let us call $c(\phi)=c(z), z \in L_{c}(\phi)$, and consider the following program:

$$
\begin{aligned}
& {[\operatorname{Pr}(\phi)] \text { Min }\left[\begin{array}{ll}
\sum_{i} & t_{i}
\end{array}\right]} \\
& \text { s.t. } t \in Z(\phi) \\
& c(t) \geq c(\phi)
\end{aligned}
$$

Program $[\operatorname{Pr}(\phi)]$ always has a solution, since $\{t \in \mathrm{Z}(\phi) \mid \mathrm{c}(\mathrm{t}) \geq \mathrm{c}(\phi)\}$ is compact and nonempty. Let us call $\mathrm{S}(\phi)=\{\mathrm{t} \in \mathrm{Z}(\phi) \mid \mathrm{t}$ solves $\operatorname{Pr}(\phi)\}$. Then, $\mathrm{S}(\phi) \subset \mathrm{L}_{\mathrm{c}}(\phi), \mathrm{S}(\phi) \neq \varnothing$, closed and convex. If $\mathrm{L}_{\mathrm{c}}(\phi) \subset \mathrm{P}_{\mathrm{u}}(\phi)$ (as it is the case under $(\mathrm{A}))$, then $\mathrm{S}(\phi) \subset \mathrm{P}_{\mathrm{u}}(\phi)$. Nonetheless, in general $\mathrm{S}(\phi)$ is not included in $\mathrm{P}_{\mathrm{u}}(\phi)$.

EXAMPLE: Let $\phi \in \mathbb{V}, \phi=\langle 2,2,(1,1), \mathrm{c}, \mathrm{u}\rangle$, with

$$
c_{i}\left(x_{i}, y_{i}\right)=\left[\operatorname{Min}\left(x_{i}, \frac{1}{3}\right)\right]^{1 / 2}\left[\operatorname{Min}\left(y_{i}, \frac{1}{3}\right)\right]^{1 / 2}, u_{i}\left(x_{i}, y_{i}\right)=\frac{x_{i} y_{i}}{1+x_{i} y_{i}}
$$

then, the unique solution to $\operatorname{Pr}(\phi)$ is $x_{i}=\left(\frac{1}{3}, \frac{1}{3}\right), i=1,2 . u_{i}\left(\frac{1}{3}, \frac{1}{3}\right)=\frac{1}{10}$, and $\mathrm{u}_{\mathrm{i}}\left(\frac{1}{2}, \frac{1}{2}\right)=\frac{1}{5}$, that is, $\mathrm{S}(\phi)$ is not included in $\mathrm{P}_{\mathrm{u}}(\phi)$. 
Some properties on $\mathbf{S}(\phi)$ are immediate:

1) For all $\phi \in \mathbb{V}$, for all $t, z \in S(\phi), u(t)$ and $u(z)$ are either Pareto indifferent or non-comparable in $\mathscr{A}(\phi)$.

2) If $\phi \in \mathbb{V}^{*}$, then $\mathrm{S}(\phi)=\mathrm{L}_{c}(\phi)$.

It has to be noticed that $\mathrm{S}(\phi)$ is a convex set in $\mathrm{Z}(\phi)$, but $\mathrm{u}[\mathrm{S}(\phi)]$ is not convex in $\mathscr{A}(\phi)$. Moreover, even though $c(z)=c(\phi)$ for any $z \in S(\phi)$, and therefore the agents are indifferent (in capabilities term) among the elements in $\mathbf{S}(\phi)$, it is not so in utilities term.

Consider a problem $\phi=\langle\mathrm{n}, \ell, \mathrm{w}, \mathrm{c}, \mathrm{u}\rangle \in \mathbb{V}$, and choose a particular allocation $z \in S(\phi)$. Take now the problem $\phi_{\mathrm{z}}=\left\langle\ell, \mathrm{w}^{\prime}, \mathrm{c}^{\prime}, \mathrm{u}^{\prime}\right\rangle$, where $\mathrm{w}^{\prime}=\mathrm{w}$ $-\sum_{i=1}^{n} z_{i}, c_{i}^{\prime}\left(x_{i}\right)=c_{i}\left(x_{i}+z_{i}\right)-c_{i}\left(z_{i}\right) ; u_{i}^{\prime}\left(x_{i}\right)=u_{i}\left(x_{i}+z_{i}\right)-u_{i}\left(z_{i}\right)$.

Let us call $\mathbb{V}_{0}$ the set of problems in $\mathbb{V}$ such that $\mathrm{c}(\phi)=0$. If $\phi \in$ $\mathbb{V}_{0}$, then $S(\phi)=\{0\}$, that is, the unique allocation fulfilling $c(\phi)$ at a minimum cost is that allocation not giving any good to any agent. We can identify $\mathbb{V}_{0}$, therefore, with the usual bargaining in economic environments setting, since the capabilities play no role in these distribution problems. Notice that, whenever we face a problem $\phi \in \mathbb{V}$, and if $z \in S(\phi)$, then the associated problem $\phi_{z} \in \mathbb{V}_{0}$.

Consider now the following property:

Separability (Sep.): Let $\phi=\langle\mathrm{n}, \ell, \mathrm{w}, \mathrm{c}, \mathrm{u}\rangle \in \mathbb{V}$, and $\mathrm{x} \in \mathrm{F}(\phi)$. Then, $\mathrm{x}=\mathrm{z}+\mathrm{t}$, where $z \in S(\phi)$, and $t \in F\left(\phi_{z}\right)$. 
Separability deals with the way resources are allocated among agents by the mechanism $F$. In a first step, we allocate resources as for guaranteeing the "maximum equitable capability level", in the cheapest way, that is, by means of an element in $\mathrm{S}(\phi), z$. Then we face a new problem in which resources have been diminished in $z$, capabilities "disappear" of the picture, and utilities are the same as before by an adequate change of reference point. Now, the mechanism allocates the remaining resources taking into account only the information in the utility space $\mathcal{A}\left(\phi_{z}\right)$. A mechanism satisfies Separability whenever the way it allocates the resources can be viewed in this two steps manner.

In the case in which $\mathrm{u}(\mathrm{t})$ is unique for all $\mathrm{t} \in \mathrm{S}(\phi)$, it seems sensible to again improve the utilities of the agents by a lexical procedure in order to reach a Pareto Optimal point in utility terms ${ }^{(13)}$. Let us call $\hat{\mathbb{V}}$ the set of problems in $\mathbb{V}$ such that $u(t)=u(z)$, for all $t, z \in$ S(e). Now, consider the following mechanism:

$$
\mathrm{L}_{\mathrm{cu}}(\phi)=\left\{\mathrm{z} \in \mathrm{P}_{\mathrm{u}}(\phi) \mid \mathrm{z}=\mathrm{t}+\mathrm{v}, \mathrm{t} \in \mathrm{S}(\phi), \mathrm{v} \in \mathrm{L}_{\mathrm{u}}\left(\phi_{\mathrm{z}}\right)\right\}
$$

Then, the following characterization result is obtained:

Theorem 3.- If a mechanism $F$ in $\hat{V}$ satisfies weak fullness, CONRAD, CPO, UPO, AN, P.STAB, I.R.MON and Sep, then F $=L_{c u}$.

13 A way of guaranteeing the uniqueness in utilities terms of elements in $\mathrm{S}(\mathrm{e})$ is by considering the utility functions of the agents separable in primary goods (not necessarily the same for all agents) and secondary goods, in such a way that the capability index and the utility index dependent on primary goods provide with identical ordering. Then, at points in $\mathrm{S}(\mathrm{e})$ agents only enjoy primary goods, and the uniqueness of the capability indexes implies the uniqueness of the utility levels 


\section{FINAL REMARKS}

In our model two different continuous and concave functions have been attached to each individual. Both the capability index of individual $i, c_{i}$, and the utility index of individual $i, u_{i}$ induce an ordering in the commodities space. So, agent $i$ "prefers in capability terms" bundle $x_{i}$ to bundle $y_{i}$ iff $c_{i}\left(x_{i}\right)>c_{i}\left(y_{i}\right)$, and "prefers in utility terms" bundle $x_{i}$ to bundle $y_{i}$ iff $u_{i}\left(x_{i}\right)>u_{i}\left(y_{i}\right)$. In principle, both orderings are different, even in the class $\mathbb{V}$, when they are related by the implication:

$$
c_{i}\left(x_{i}\right)>c_{i}\left(y_{i}\right) \text { implies } u_{i}\left(x_{i}\right)>u_{i}\left(y_{i}\right)
$$

Then, if $u_{i}\left(x_{i}\right) \geq u_{i}\left(y_{i}\right)$, we obtain that $c_{i}\left(x_{i}\right) \geq c_{i}\left(y_{i}\right)$. Nonetheless it may occur that $c_{i}\left(x_{i}\right)=c_{i}\left(y_{i}\right)$, and $u_{i}\left(x_{i}\right) \neq u_{i}\left(y_{i}\right)$.

EXAMPLE: Suppose there are two goods, and let

$$
c_{i}\left(x_{i}, y_{i}\right)=\left[\operatorname{Min}\left(x_{i}, \frac{1}{3}\right)\right]^{1 / 2}\left[\operatorname{Min}\left(y_{i}, \frac{1}{3}\right)\right]^{1 / 2}, u_{i}\left(x_{i}, y_{i}\right)=\frac{x_{i} y_{i}}{1+x_{i} y_{i}}
$$

then, $c_{i}\left(\frac{1}{2}, \frac{1}{2}\right)=c_{i}\left(\frac{1}{2}, \frac{1}{3}\right)=\frac{1}{3}$ but $u_{i}\left(\frac{1}{2}, \frac{1}{3}\right)=\frac{1}{7} \quad u_{i}\left(\frac{1}{2}, \frac{1}{2}\right)=\frac{1}{5}$

Under the additional hypothesis of (A), $c_{i}$-ordering and $u_{i}$-ordering are the same. For in that case, suppose that $x_{i}, y_{i}$ exist such that $c_{i}\left(x_{i}\right)$ $=c_{i}\left(y_{i}\right)$, with $u_{i}\left(x_{i}\right)<u_{i}\left(y_{i}\right)$. Then, we can find $x_{i}^{n} \in N\left(x_{i}, 1 / n\right)$ such that $c_{i}\left(y_{i}\right)=c_{i}\left(x_{i}\right)<c_{i}\left(x_{i}^{n}\right)$, and therefore, $u_{i}\left(x_{i}\right)<u_{i}\left(y_{i}\right)<u_{i}\left(x_{i}^{n}\right)$. Now, by letting $n \rightarrow \infty, u_{i}\left(x_{i}\right)>u_{i}\left(y_{i}\right)$. Contradiction. 
In Proposition 2 we saw that under (A), $\mathrm{P}_{c}(\mathrm{e}) \subset \mathrm{P}_{\mathrm{u}}(\mathrm{e})$. Nonetheless, the reverse inclusion does not hold. Consider the following example:

$e \in \mathbb{V}^{*}, e=\langle 2,2,(1,1), c, u\rangle$, where

$$
c_{1}\left(x_{1}, y_{1}\right)=\left[\operatorname{Min}\left(x_{1}, \frac{1}{3}\right)\right]^{1 / 2}\left[\operatorname{Min}\left(y_{1}, \frac{1}{3}\right)\right]^{1 / 2}, u_{i}\left(x_{i}, y_{i}\right)=\frac{x_{i} y_{i}}{1+x_{i} y_{i}}, i=1,2
$$

$c_{2}\left(x_{2}, y_{2}\right)=x_{2} y_{2}$. Then, the allocation $z=\left[\left(\frac{1}{2}, \frac{1}{2}\right),\left(\frac{1}{2}, \frac{1}{2}\right)\right] \in P_{u}(e)$, but does not belong to $\mathrm{P}_{c}(e)$, since $c_{1}\left(\frac{1}{2}, \frac{1}{2}\right)=\frac{1}{3}, c_{2}\left(\frac{1}{2}, \frac{1}{2}\right)=\frac{1}{4}$, and if we consider the allocation $t=\left[\left(\frac{1}{3}, \frac{1}{3}\right),\left(\frac{2}{3}, \frac{2}{3}\right)\right], c_{1}\left(\frac{1}{3}, \frac{1}{3}\right)=\frac{1}{3}, c_{2}\left(\frac{2}{3}, \frac{2}{3}\right)=\frac{4}{9}$, and $c(t)>c(z)$.

It is also worth noticing that, even if (A) holds for all $i=1, \ldots, n$, that is, if all the orderings induced by the utility functions $u_{1}, \ldots, u_{n}$ coincide on $\mathbf{X}$ with those induced by the capability functions $c_{1}, \ldots, c_{n}$, respectively, the utilities associated to vectors in $L_{c}(e)$ are not leximin suprema [since the relationship between $u_{i}$ and $c_{i}$ is ordinal].

EXAMPLE: Let $\phi \in \mathbb{V}, \quad \phi=\langle 2,2,(1,1), \mathrm{c}, \mathrm{u}\rangle$, where $\mathrm{c}_{\mathrm{i}}\left(\mathrm{x}_{\mathrm{i}}, \mathrm{y}_{\mathrm{i}}\right)=\mathrm{x}_{\mathrm{i}}^{1 / 2} \mathrm{y}_{\mathrm{i}}^{1 / 2}$, $\mathrm{i}=1,2, \mathrm{u}_{1}\left(\mathrm{x}_{1}, \mathrm{y}_{1}\right)=\mathrm{x}_{1} \mathrm{y}_{1}, \mathrm{u}_{2}\left(\mathrm{x}_{2}, \mathrm{y}_{2}\right)=\mathrm{x}_{2}^{1 / 4} \mathrm{y}_{2}^{1 / 4}$.

Then the allocation $z=\left[\left(\frac{1}{2}, \frac{1}{2}\right),\left(\frac{1}{2}, \frac{1}{2}\right)\right] \in L_{c}(\phi) ; \quad c_{1}\left(z_{1}\right)=c_{2}\left(z_{2}\right)=\frac{1}{2}$;

$u_{1}\left(z_{1}\right)=\frac{1}{4} ; \quad u_{2}\left(z_{2}\right)=\frac{1}{2^{1 / 2}}$. Consider now the allocation $t=\left[\left(\frac{2}{3}, \frac{2}{3}\right),\left(\frac{1}{3}, \frac{1}{3}\right)\right]$ $u_{1}\left(t_{1}\right)=\frac{4}{9} ; u_{2}\left(t_{2}\right)=\frac{1}{3^{1 / 2}} ;$ and thus, $u(t)>^{L m} u(z)$ 
If utilities associated to elements in $S(\phi)$ are not unique, the result in Theorem 3 no longer holds. In such a case, agents are not indifferent between the elements in $\mathrm{S}(\phi)$. In such a case, an interesting property would be the following:

Concavity (CAV): Let $\phi=\langle\mathrm{n}, \ell, \mathrm{w}, \mathrm{c}, \mathrm{u}\rangle \in \mathbb{V}, \mathrm{z}, \mathrm{t} \in \mathrm{S}(\phi)$, and assume $\mathrm{z}^{\prime} \in \mathrm{F}\left(\phi_{\mathrm{z}}\right)$, $\mathrm{t}^{\prime} \in \mathrm{F}\left(\phi_{\mathrm{t}}\right)$. Then, if $\mathrm{h} \in \mathrm{F}\left(\mathrm{e}_{\lambda z+(1-\lambda) \mathrm{t}}\right), \mathrm{u}[\lambda z+(1-\lambda) \mathrm{t}+\mathrm{h}]=\lambda \mathrm{u}\left(\mathrm{z}+\mathrm{z}^{\prime}\right)+$ $(1-\lambda) u\left(t+t^{\prime}\right)$.

Concavity is a version in economic environments of the axiom disagreement point concavity [D.CAV.], used by Chun \& Thomson (1990) in the context of bargaining with uncertain disagreement point. The idea underlying this axiom is the following: suppose we choose at random a point $(z)$ in $S(\phi)$, and we use this point as a starting point of the corresponding associated problem $\left(\phi_{z}\right)$. In capabilities terms, there is no any difference since all the proposed solutions give rise to the common capabilities point $c(\phi)$. Now, in utilities terms, some agents prefer specific points in $\mathrm{S}(\phi)$. Under CAV., agents prefer to solve the uncertainty by choosing a compromise point $\lambda z+(1-\lambda) t$, than wait, since their utility in the first case is higher than their expected utility in the second one.

Now, it seems sensible to identify those allocation mechanisms in $\mathbb{V}$ fulfilling the aforementioned property. It is left for future work. 


\section{A P P E N D I X}

Some properties play an intermediate role in the characterization result of theorem 1 :

Welfarism (W): Let $\phi=\langle\mathrm{n}, \ell, \mathrm{w}, \mathrm{c}\rangle$ and $\phi^{\prime}=\left\langle\mathrm{n}, \ell^{\prime}, \mathrm{w}^{\prime}, \mathrm{c}^{\prime}\right\rangle \in \sum$ such that $\mathscr{C}(\phi)=$ $\mathscr{C}\left(\phi^{\prime}\right)$. Then, $c[F(\phi)]=c\left[F\left(\phi^{\prime}\right)\right]$.

Welfarism says that the mechanism must treat identically (in terms of capabilities) any two economic environments with the same number of agents and identical capabilities possibilities set.

Contraction Consistency (CC): Let $\phi=\langle\mathrm{n}, \ell, \mathrm{w}, \mathrm{c}\rangle$ and $\phi^{\prime}=\left\langle\mathrm{n}, \ell^{\prime}, \mathrm{w}^{\prime}, \mathrm{c}^{\prime}\right\rangle$ two problems in $\sum$ such that $\mathscr{C}\left(\phi^{\prime}\right) \subset \mathscr{C}(\phi), c[F(\phi)] \subset \mathscr{C}\left(\phi^{\prime}\right)$. Then, $c^{\prime}[F(\phi)]$ $=c[F(\phi)]$.

\section{Lemma 1.- CONRAD and fullness of F imply W.}

PROOF: Let $\phi=\langle\mathrm{n}, \ell, \mathrm{w}, \mathrm{c}\rangle, \phi^{\prime}=\left\langle\mathrm{n}, \ell^{\prime}, \mathrm{w}^{\prime}, \mathrm{c}^{\prime}\right\rangle$ such that $\mathscr{C}(\phi)=\mathscr{C}\left(\phi^{\prime}\right)$. We have to prove that $c[F(\phi)]=c^{\prime}\left[F\left(\phi^{\prime}\right)\right]$.

1. Construct $\phi^{*}=\phi \otimes \phi^{\prime} \cdot \phi^{*}=\left\langle\mathrm{n}, \ell+\ell^{\prime},\left(\mathrm{w}, \mathrm{w}^{\prime}\right), \mathrm{d}\right\rangle$, where $\mathrm{d}_{\mathrm{i}}\left(\mathrm{x}_{\mathrm{i}}, \mathrm{y}_{\mathrm{i}}\right)=\min$ $\left\{c_{i}\left(x_{i}\right), c_{i}^{\prime}\left(y_{i}\right)\right\}$. By Billera \& Bixby (1973), $\mathscr{C}\left(\phi^{*}\right)=\mathscr{C}(\phi)=\mathscr{C}\left(\phi^{\prime}\right)$.

We shall prove that $\mathrm{d}\left[\mathrm{F}\left(\phi^{*}\right)\right]=\mathrm{c}[\mathrm{F}(\phi)]$. In a similar way, the analogous relationships for $\phi^{\prime}$ and $\phi^{*}$ are obtained, and the lemma follows. 
2. Consider now $\bar{\phi}=\left\langle n, \ell+\ell^{\prime},\left(\mathrm{w}, \mathrm{w}^{\prime}\right), \overline{\mathrm{c}}\right\rangle$, where $\bar{c}_{\mathrm{i}}\left(\mathrm{x}_{\mathrm{i}}, \mathrm{y}_{\mathrm{i}}\right)=\mathrm{c}_{\mathrm{i}}\left(\mathrm{x}_{\mathrm{i}}\right), \quad \mathrm{i}=$ $1, \ldots$, n. Obviously, $\mathscr{C}(\bar{\phi})=\mathscr{C}(\phi)$. We can apply CONRAD to $\phi, \bar{\phi}$, and then we get that if $(\mathrm{x}, \mathrm{y}) \in \mathrm{F}(\bar{\phi})$, then $\mathrm{x} \in \mathrm{F}(\phi)$, and therefore $c[F(\phi)]=\bar{c}[F(\bar{\phi})]$.

3. Notice that $\bar{c}_{i}\left(x_{i}, y_{i}\right) \geq d_{i}\left(x_{i}, y_{i}\right)$, for all $i=1, \ldots, n$. Now, by Howe (1987, prop.3), it is possible to find functions $C_{i}: \mathbb{R}^{\ell+\ell^{\prime}+1}--\rightarrow \mathbb{R}$, such that

$$
C_{i}\left(x_{i}, y_{i}, 1\right)=\bar{c}_{i}\left(x_{i}, y_{i}\right), C_{i}\left(x_{i}, y_{i}, 0\right)=d_{i}\left(x_{i}, y_{i}\right) .
$$

Now, construct the functions $D_{i}: \mathbb{R}^{\ell+\ell^{\prime}+n}-->\mathbb{R}$, such that $D_{i}\left(x_{i}, y_{i}, z\right)=$ $C_{i}\left(x_{i}, y_{i}, z_{i}\right)$, for $z \in \mathbb{R}^{n}, i=1, \ldots, n$.

4. Consider now the problem $\bar{\phi}^{*}=\left\langle\mathrm{n}, \ell+\ell^{\prime}+\mathrm{n}\right.$, $\left.\left(\mathrm{w}, \mathrm{w}^{\prime}, 1,1, \ldots, 1\right), \mathrm{D}\right\rangle$. $\mathscr{C}\left(\bar{\phi}^{*}\right)=$ $\mathscr{C}(\bar{\phi})=\mathscr{C}(\phi)$. By CONRAD, if $(\mathrm{x}, \mathrm{y}, \mathrm{z}) \in \mathrm{F}\left(\bar{\phi}^{*}\right), \quad(\mathrm{x}, \mathrm{y}) \in \mathrm{F}(\bar{\phi})$, and therefore $\mathrm{D}\left[\mathrm{F}\left(\bar{\phi}^{*}\right)\right]=\overline{\mathrm{c}}[\mathrm{F}(\bar{\phi})]$.

5. Let now $\phi^{* *}=\left\langle\mathrm{n}, \ell+\ell^{\prime}+\mathrm{n},\left(\mathrm{w}, \mathrm{w}^{\prime}, 0\right), \mathrm{D}\right\rangle, 0 \in \mathbb{R}^{\mathrm{n}}$. Again, $\mathscr{C}\left(\phi^{* *}\right)=\mathscr{C}\left(\phi^{*}\right)$. By CONRAD, $\mathrm{D}\left[\mathrm{F}\left(\phi^{* *}\right)\right]=\mathrm{d}\left[\mathrm{F}\left(\phi^{*}\right)\right]$.

6. From previous constructions, $\mathscr{C}\left(\phi^{* *}\right)=\mathscr{C}\left(\bar{\phi}^{*}\right)$. Consider an allocation in $F\left(\bar{\phi}^{*}\right), \quad z_{i}=\left(x_{i}, y_{i}, \zeta_{i}\right)$, where $\zeta_{i}$ is the ith vector of the canonical basis in $\mathbb{R}^{\mathrm{n}}$. Then, there must be an allocation $t_{i}=\left(x_{i}^{\prime}, x, 0\right)$ in $Z\left(\phi^{* *}\right)$, inducing the same capabilities point, $D(z)=D(t)$. Thus, since $t$ is feasible in $\bar{\phi}^{*}$, and because of fullness of $F, t \in F\left(\bar{\phi}^{*}\right)$.

Now, by CONRAD, $\left(\mathrm{x}, \mathrm{y}_{\mathrm{i}}^{\prime}\right)_{\mathrm{i}=1, \ldots, \mathrm{n}} \in \mathrm{F}\left(\phi^{*}\right)$, obtaining that $\mathrm{d}\left[\mathrm{F}\left(\phi^{*}\right)\right]=$ $\mathrm{D}\left[\mathrm{F}\left(\bar{\phi}^{*}\right)\right]$. And therefore, $\mathrm{d}\left[\mathrm{F}\left(\phi^{*}\right)=\mathrm{c}[\mathrm{F}(\phi)]\right.$. 
Lemma 2.- CONRAD and fullness imply CC.

PROOF: Let $\phi=\langle\mathrm{n}, \ell, \mathrm{w}, \mathrm{c}\rangle$, and $\phi^{\prime}=\left\langle\mathrm{n}, \ell^{\prime}, \mathrm{w}^{\prime}, \mathrm{c}^{\prime}\right\rangle$ two problems in $\sum$ such that $\mathscr{C}\left(\phi^{\prime}\right) \subset \mathscr{C}(\phi)$, with $c[F(\phi)] \subset \mathscr{C}\left(\phi^{\prime}\right)$. To show: $c^{\prime}\left[F\left(\phi^{\prime}\right)\right]=c[F(\phi)]$. Notice that $\mathrm{F}$ satisfies $\mathrm{W}$, by lemma 1 , since SCONRAD implies CONRAD.

1. In the same way as in lemma 1 , steps 1 to 5 , construct $\bar{\phi}^{*}=<n, \ell+\ell^{\prime}+n$, $\left.\left(\mathrm{w}, \mathrm{w}^{\prime}, 1,1, \ldots, 1\right), \mathrm{D}\right\rangle$ and $\phi^{* *}=\left\langle\mathrm{n}, \ell+\ell^{\prime}+\mathrm{n}, \quad\left(\mathrm{w}, \mathrm{w}^{\prime}, 0\right), \mathrm{D}\right\rangle$. We have that $\mathscr{G}(\phi)=$ $\mathscr{C}\left(\bar{\phi}^{*}\right)$, and $\mathscr{C}\left(\phi^{\prime}\right)=\mathscr{C}\left(\phi^{* *}\right)$. Thus, by $\mathrm{W}, \mathrm{c}[\mathrm{F}(\phi)]=\mathrm{D}\left[\mathrm{F}\left(\bar{\phi}^{*}\right)\right]$, and $\mathrm{c}^{\prime}\left[\mathrm{F}\left(\phi^{\prime}\right)\right]=$ $\mathrm{D}\left[\mathrm{F}\left(\phi^{* *}\right)\right]$.

2. $\mathrm{D}\left[\mathrm{F}\left(\bar{\phi}^{*}\right)\right] \subset \mathscr{C}\left(\phi^{* *}\right)$. Consider an allocation in $\mathrm{F}\left(\bar{\phi}^{*}\right), \mathrm{z}_{\mathrm{i}}=\left(\mathrm{x}_{\mathrm{i}}, \mathrm{y}_{\mathrm{i}}, \zeta_{\mathrm{i}}\right)$, where $\zeta_{\mathbf{i}}$ is the ith vector of the canonical basis in $\mathbb{R}^{n}$. Thus, there is an allocation $t_{i}=\left(x_{i}^{\prime}, y_{i}^{\prime}, 0\right)$ in $Z\left(\phi^{* *}\right)$, inducing the same capabilities point, i.e., $D(z)=D(t)$. Thus, since $t$ is feasible in $\bar{\phi}^{*}$, and because of fullness of $\mathrm{F}, \mathrm{t} \in \mathrm{F}\left(\bar{\phi}^{*}\right)$.

3. Let $\phi_{1}^{* *}$ be the problem obtained by taking the CONRAD restriction of $\phi^{* *}$ with respect to the last $\mathrm{n}$ components of $\mathrm{t}$. Then, $\mathscr{C}\left(\phi^{* *}\right)=\mathscr{C}\left(\phi_{1}^{* *}\right)=$ $\mathscr{C}\left(\phi^{\prime}\right)$.

4. By CONRAD, $\mathrm{D}[\mathrm{F}(\phi)]=\mathrm{D}\left[\mathrm{F}\left(\phi_{1}^{* *}\right)\right]$. By previous step, and $\mathrm{W}, \mathrm{c}^{\prime}\left[\mathrm{F}\left(\phi^{\prime}\right)\right]=$ $c[F(\phi)]$.

PROOF OF THEOREM 1:

1. $\mathrm{L}_{\mathrm{c}}$ satisfies all the properties. Let us see that if a mechanism $\mathrm{F}$ satisfies the properties, then $\mathrm{F}=\mathrm{L}_{\mathrm{c}}$. 
2. Let us consider $\phi=\langle\mathrm{n}, \ell, \mathrm{w}, \mathrm{c}\rangle \in \sum$, and let $\mathrm{z} \in \mathrm{L}_{\mathrm{c}}$ (e $\phi$. Consider now $c(z)=c(\phi)$. By anonymity, we can rename the indexes in such a way that $c_{1}\left(z_{1}\right) \leq c_{2}\left(z_{2}\right) \leq \ldots \leq c_{n}\left(z_{n}\right)$. Among the previous numbers, there are only $k(0 \leq k \leq n)$ different, $a_{1}, \ldots, a_{k}$. Call $N_{j}=\left\{i \in N \mid a_{j} \geq c_{i}\left(z_{i}\right)\right\}$. Thus, $\mathrm{N}_{1} \subset \mathrm{N}_{2} \subset \ldots \subset \mathrm{N}_{\mathrm{k}}=\mathrm{N}$.

3. Let us see now that $c_{i}\left(t_{i}\right)=a_{1}$ for $i \in N_{1}$, for any $t \in F(\phi)$. Suppose there exists $t \in F(\phi)$, such that $c_{i}\left(t_{i}\right)=b<a_{1}$.

Construct $\phi^{\prime}=\left\langle n, \ell+1,(w, 1), c^{\prime}\right\rangle$ such that for $i \neq j, c_{j}^{\prime}\left(x_{j}, y_{j}\right)=c_{j}\left(x_{j}\right)$, $c_{i}^{\prime}\left(x_{i}, y_{i}\right)=y_{i} c_{i}\left(x_{i}\right) ; \quad$ Thus, $\mathscr{C}(\phi)=\mathscr{C}\left(\phi^{\prime}\right)$. By $w, c[F(\phi)]=c^{\prime}\left[F\left(\phi^{\prime}\right)\right]$. So, there exists $(x, y) \in F\left(\phi^{\prime}\right)$, such that $c_{i}^{\prime}\left(x_{i}, y_{i}\right)=b<a_{i}$.

Since the last good is a personal good for individual i in $\phi^{\prime}$, we can construct $\phi^{\prime \prime}=\left\langle\mathrm{n}, \ell+1,(\mathrm{w}, \alpha), \mathrm{c}^{\prime}\right\rangle$, with $\alpha<1$, and such that $(\mathrm{x}, \mathrm{y}) \in \mathrm{Z}(\phi)$. Now, by $C C,(x, y) \in F\left(\phi^{\prime \prime}\right)$, against I.R.MON. Thus, $c_{i}\left(t_{i}\right) \geq a_{1}$. If $c_{i}\left(t_{i}\right)>a_{1}$, there must be a point $y \in Z(\phi)$, such that $c(y)=\lambda c(t)+$ $(1-\lambda) c(z)$. But then, $c(y)>^{L} c(z)$, against the definition of $L_{c}(\phi)$. Therefore, $c_{i}\left(t_{i}\right)=a_{1}$ for all $i \in N_{1}$.

4. Let us now consider the problem $\phi_{M, F}$, where $M=N \backslash N_{1}$, and the individuals in $\mathrm{N}_{1}$ left with $\mathrm{t}_{\mathrm{N}_{1}}$. By STAB. we know that $t_{M} \in F\left(\phi_{M, F, t}\right)$. For this problem, and since $\mathrm{L}_{c}$ satisfies STAB., we know that the smallest value of $\mathrm{c}_{\mathrm{i}}\left(\phi_{\mathrm{M}, \mathrm{F}, \mathrm{t}}\right)$ is $\mathrm{a}_{2}$. By a similar argument, we arrive, in a finite number of steps, to the conclusion that $c(t)=c(\phi)$, for any $t \in F(\phi)$.

5. As a consequence, $F(\phi) \subset \mathrm{L}_{c}(\phi)$.

6. Suppose now we have $z \in L_{c}(\phi)$. Then, $c(z)=c(t)$ for any $t \in F(\phi)$. Thus, by fullness, $z \in F(\phi)$. 
Arneson, R. (1989), Equality of opportunity for welfare, Philosophical Studies, 56, pp. 77-93.

Billera, L.J. \& Bixby, R.E. (1973), A Characterization of Pareto Surfaces, Proceedings of the American Mathematical Society, 41, n. 1, pp. 261-267.

Bossert, W. (1993), Redistribution Mechanisms based on Individual Characteristics, Mimeo, University of Waterloo.

Chun, Y. \& Thomson, W. (1990), Bargaining with Uncertain Disagreement Points, Econometrica, 58, n. 4, pp. 951-959.

Cohen, G.A. (1989), On the Currency of Egalitarian Justice, Ethics, 99, pp. 906-944.

Dworkin, R. (1981), Equality of Welfare, Philosophy and Public Affairs, 10, pp. $185-246$.

Howe, R. (1987), Sections and Extensions of Concave Functions, Journal of Mathematical Economics, 16, pp. 53-64.

Kreps, D. (1979), A Representation Theorem for "Preference for Flexibility", Econometrica, 47, pp.

Lancaster, K.J. (1966), A New Approach to Consumer Theory, Journal of Political Economy, 74, pp. 132-157.

Pereira, J. (1993), What does Equality in Health mean?, Journal of Social Policy, 22, pp. 19-48. 
Puppe, C. (1994), Freedom of Choice and Rational Decisions, Mimeo, Universitat Wien.

Rawls, J. (1971), A Theory of Justice, Cambridge, Mass.: Harvard University Press.

Rawls, J. (1982), Social Unity and Primary Goods, in A. Sen \& B. Williams (eds), Utilitarianism and Beyond, Cambridge: Cambridge University Press.

Roemer, J.E. (1988), Axiomatic Bargaining Theory on Economic Environments, Journal of Economic Theory, 45, pp. 1-31.

Roemer, J.E. (1994a), Primary Goods, Fundamental Preferences and Functionings, Mimeo, University of California, Davis.

Roemer, J.E. (1994), On a Mechanism for Implementing Egalitarianism with Responsibility, Mimeo, University of California, Davis.

Sen, A.K. (1980), Equality of What?, in S. McMurrin (ed.), The Tanner Lectures of Human Values, Vol I, Salt Lake City: University of Utah Press.

Sen, A.K. (1985), Commodities and Capabilities, Amsterdam: North-Holland.

Sen, A.K. (1992), Inequality Reexamined, Oxford: Oxford University Press.

Sen, A.K. (1993), Capability and well-being, in M.C. Nussbaum and A.K. Sen (eds.), The Quality of Life, Oxford: Clarendon Press.

Thomson, W. \& Lensberg, T. (1989), Axiomatic Theory of Bargaining with a Variable Number of Agents, Cambridge: Cambridge University Press. 


\section{PUBLISHED ISSUES}

WP-AD 90-01 "Vector Mappings with Diagonal Images"

C. Herrero, A.Villar. December 1990.

WP-AD 90-02 "Langrangean Conditions for General Optimization Problems with Applications to Consumer Problems"

J.M. Gutierrez, C. Herrero. December 1990.

WP-AD 90-03 "Doubly Implementing the Ratio Correspondence with a 'Natural' Mechanism"

L.C. Corchón, S. Wilkie. December 1990.

WP-AD 90-04 "Monopoly Experimentation"

L. Samuelson, L.S. Mirman, A. Urbano. December 1990.

WP-AD 90-05 "Monopolistic Competition: Equilibrium and Optimality"

L.C. Corchón. December 1990.

WP-AD 91-01 "A Characterization of Acyclic Preferences on Countable Sets"

C. Herrero, B. Subiza. May 1991.

WP-AD 91-02 "First-Best, Second-Best and Principal-Agent Problems"

J. Lopez-Cuñat, J.A. Silva. May 1991.

WP-AD 91-03 "Market Equilibrium with Nonconvex Technologies"

A. Villar. May 1991.

WP-AD 91-04 "A Note on Tax Evasion"

L.C. Corchón. June 1991.

WP-AD 91-05 "Oligopolistic Competition Among Groups"

L.C. Corchón. June 1991.

WP-AD 91-06 "Mixed Pricing in Oligopoly with Consumer Switching Costs"

A.J. Padilla. June 1991.

WP-AD 91-07 "Duopoly Experimentation: Cournot and Bertrand Competition"

M.D. Alepuz, A. Urbano. December 1991.

WP-AD 91-08 "Competition and Culture in the Evolution of Economic Behavior: A Simple Example"

F. Vega-Redondo. December 1991.

WP-AD 91-09 "Fixed Price and Quality Signals"

L.C. Corchón. December 1991.

WP-AD 91-10 "Technological Change and Market Structure: An Evolutionary Approach"

F. Vega-Redondo. December 1991.

WP-AD 91-11 "A 'Classical' General Equilibrium Model"

A. Villar. December 1991.

WP-AD 91-12 "Robust Implementation under Alternative Information Structures"

L.C. Corchón, I. Ortuño. December 1991. 
WP-AD 92-01 "Inspections in Models of Adverse Selection"

I. Ortuño. May 1992.

WP-AD 92-02 "A Note on the Equal-Loss Principle for Bargaining Problems"

C. Herrero, M.C. Marco. May 1992.

WP-AD 92-03 "Numerical Representation of Partial Orderings"

C. Herrero, B. Subiza. July 1992.

WP-AD 92-04 "Differentiability of the Value Function in Stochastic Models"

A.M. Gallego. July 1992.

WP-AD 92-05 "Individually Rational Equal Loss Principle for Bargaining Problems"

C. Herrero, M.C. Marco. November 1992.

WP-AD 92-06 "On the Non-Cooperative Foundations of Cooperative Bargaining"

L.C. Corchón, K. Ritzberger. November 1992.

WP-AD 92-07 "Maximal Elements of Non Necessarily Acyclic Binary Relations"

J.E. Peris, B. Subiza. December 1992.

WP-AD 92-08 "Non-Bayesian Learning Under Imprecise Perceptions"

F. Vega-Redondo. December 1992.

WP-AD 92-09 "Distribution of Income and Aggregation of Demand"

F. Marhuenda. December 1992.

WP-AD 92-10 "Multilevel Evolution in Games"

J. Canals, F. Vega-Redondo. December 1992.

WP-AD 93-01 "Introspection and Equilibrium Selection in 2x2 Matrix Games"

G. Olcina, A. Urbano. May 1993.

WP-AD 93-02 "Credible Implementation"

B. Chakravorti, L. Corchón, S. Wilkie. May 1993.

WP-AD 93-03 "A Characterization of the Extended Claim-Egalitarian Solution" M.C. Marco. May 1993.

WP-AD 93-04 "Industrial Dynamics, Path-Dependence and Technological Change" F. Vega-Redondo. July 1993.

WP-AD 93-05 "Shaping Long-Run Expectations in Problems of Coordination" F. Vega-Redondo. July 1993.

WP-AD 93-06 "On the Generic Impossibility of Truthful Behavior: A Simple Approach" C. Beviá, L.C. Corchón. July 1993.

WP-AD 93-07 "Cournot Oligopoly with 'Almost' Identical Convex Costs" N.S. Kukushkin. July 1993.

WP-AD 93-08 "Comparative Statics for Market Games: The Strong Concavity Case" L.C. Corchón. July 1993.

WP-AD 93-09 "Numerical Representation of Acyclic Preferences" B. Subiza. October 1993. 
WP-AD 93-10 "Dual Approaches to Utility"

M. Browning. October 1993.

WP-AD 93-11 "On the Evolution of Cooperation in General Games of Common Interest"

F. Vega-Redondo. December 1993.

WP-AD 93-12 "Divisionalization in Markets with Heterogeneous Goods"

M. González-Maestre. December 1993.

WP-AD 93-13 "Endogenous Reference Points and the Adjusted Proportional Solution for Bargaining Problems with Claims"

C. Herrero. December 1993.

WP-AD 94-01 "Equal Split Guarantee Solution in Economies with Indivisible Goods Consistency and Population Monotonicity"

C. Beviá. March 1994.

WP-AD 94-02 "Expectations, Drift and Volatility in Evolutionary Games"

F. Vega-Redondo. March 1994.

WP-AD 94-03 "Expectations, Institutions and Growth"

F. Vega-Redondo. March 1994.

WP-AD 94-04 "A Demand Function for Pseudotransitive Preferences"

J.E. Peris, B. Subiza. March 1994.

WP-AD 94-05 "Fair Allocation in a General Model with Indivisible Goods"

C. Beviá. May 1994.

WP-AD 94-06 "Honesty Versus Progressiveness in Income Tax Enforcement Problems"

F. Marhuenda, I. Ortuño-Ortín. May 1994.

WP-AD 94-07 "Existence and Efficiency of Equilibrium in Economies with Increasing Returns to Scale: An Exposition"

A. Villar. May 1994.

WP-AD 94-08 "Stability of Mixed Equilibria in Interactions Between Two Populations"

A. Vasin. May 1994.

WP-AD 94-09 "Imperfectly Competitive Markets, Trade Unions and Inflation: Do Imperfectly Competitive Markets Transmit More Inflation Than Perfectly Competitive Ones? A Theoretical Appraisal" L. Corchón. June 1994.

WP-AD 94-10 "On the Competitive Effects of Divisionalization"

L. Corchón, M. González-Maestre. June 1994.

WP-AD 94-11 "Efficient Solutions for Bargaining Problems with Claims" M.C. Marco-Gil. June 1994.

WP-AD 94-12 "Existence and Optimality of Social Equilibrium with Many Convex and Nonconvex Firms" A. Villar. July 1994.

WP-AD 94-13 "Revealed Preference Axioms for Rational Choice on Nonfinite Sets" J.E. Peris, M.C. Sánchez, B. Subiza. July 1994. 
WP-AD 94-14 "Market Learning and Price-Dispersion"

M.D. Alepuz, A. Urbano. July 1994.

WP-AD 94-15 "Bargaining with Reference Points - Bargaining with Claims: Egalitarian Solutions Reexamined"

C. Herrero. September 1994.

WP-AD 94-16 "The Importance of Fixed Costs in the Design of Trade Policies: An Exercise in the Theory of Second Best"

L. Corchón, M. González-Maestre. September 1994.

WP-AD 94-17 "Computers, Productivity and Market Structure"

L. Corchón, S. Wilkie. October 1994.

WP-AD 94-18 "Fiscal Policy Restrictions in a Monetary System: The Case of Spain"

M.I. Escobedo, I. Mauleón. December 1994.

WP-AD 94-19 "Pareto Optimal Improvements for Sunspots: The Golden Rule as a Target for Stabilization" S.K. Chattopadhyay. December 1994.

WP-AD 95-01 "Cost Monotonic Mechanisms"

M. Ginés, F. Marhuenda. March 1995.

WP-AD 95-02 "Implementation of the Walrasian Correspondence by Market Games"

L. Corchón, S. Wilkie. March 1995.

WP-AD 95-03 "Terms-of-Trade and the Current Account: A Two-Country/Two-Sector Growth Model" M.D. Guilló. March 1995.

WP-AD 95-04 "Exchange-Proofness or Divorce-Proofness? Stability in One-Sided Matching Markets" J. Alcalde. March 1995.

WP-AD 95-05 "Implementation of Stable Solutions to Marriage Problems"

J. Alcalde. March 1995.

WP-AD 95-06 "Capabilities and Utilities"

C. Herrero. March 1995.

WP-AD 95-07 "Rational Choice on Nonfinite Sets by Means of Expansion-Contraction Axioms" M.C. Sánchez. March 1995.

WP-AD 95-08 "Veto in Fixed Agenda Social Choice Correspondences" M.C. Sánchez, J.E. Peris. March 1995.

WP-AD 95-09 "Temporary Equilibrium Dynamics with Bayesian Learning" S. Chatterji. March 1995. 